\title{
Tradiciones discursivas, historia de la lengua española e historia del portugués brasileño. Fundamentos teóricos, principios metodológicos y aproximaciones descriptivas"
}

\author{
Araceli López Serena \\ https://orcid.org/0000-0001-6987-6551 \\ Universidad de Sevilla \\ cheilop@us.es
}

\section{RESUMEN}

El presente artículo analiza la recepción del concepto de tradición discursiva (TD) en la investigación lingüística hispánica y brasileña y da cuenta

\footnotetext{
El presente trabajo se enmarca dentro del proyecto "Tradicionalidad discursiva, tradicionalidad idiomática, sintaxis del discurso, traducción y cambio lingüístico en la historia del español moderno: prosa (pre-) periodística, prosa (pre-)ensayística y prosa literaria” (PGC2018-097823-BI00)," financiado por el Ministerio de Economía y Competitividad del Gobierno de España. Agradezco a los hispanistas Rafael Cano Aguilar, Mónica Castillo Lluch, Santiago del Rey Quesada, Alfonso Gallegos Shibya, Carlos Garatea Grau, Martha Guzmán Riverón, Álvaro Octavio de Toledo y Huerta, Lola Pons Rodríguez y María Eugenia Vázquez Laslop, así como a los lusitanistas José da Silva Simões, Alessandra Castilho da Costa y Verena Kewitz las sugerencias y los materiales bibliográficos que me han hecho llegar en varios momentos de la investigación que ha conducido a la redacción de este artículo. Estoy asimismo en deuda con los dos revisores anónimos de la revista Lexis, cuyas observaciones han contribuido, sin duda alguna, a mejorar el resultado final de estas páginas, de las que se encuentra también en preparación una síntesis, en inglés, que con el título "International Diffusion of the Discourse Traditions Model" formará parte del Manual of Discourse Traditions in Romance coordinado por Álvaro Octavio de Toledo y Esme Winter-Froemel para la editorial De Gruyter.
}

https://doi.org/10.18800/lexis.202102.001 
de los principios, métodos y orientaciones que han dado sustento a este enfoque de análisis en España, Hispanoamérica y Brasil, con el propósito de ser de utilidad tanto para quienes necesiten informarse sobre las principales referencias que cabe destacar, en los ámbitos regionales acotados para este estudio, en relación con el paradigma de las TD, como, sobre todo, para quienes busquen hacerse una idea acerca de los pilares metodológicos en que se asienta esta corriente de la lingüística histórica.

Palabras clave: tradiciones discursivas, historia de la lengua española, historia del portugués brasileño, lingüística histórica, cambio lingüístico

Discourse Traditions in Spanish and Brazilian Historical Linguistics. Theoretical Foundations, Methodological Principles and Descriptive Approaches

\begin{abstract}
This article analyses the reception of the concept of discourse tradition (DT) in Hispanic and Brazilian linguistic research. It gives an account of the principles, methods and orientations that have underpinned this approach to analysis in Spain, Latin America and Brazil. Its purpose is to be useful both for those who need information on the main references to be highlighted, in the regional areas delimited for this study, in relation to the DTs paradigm, and, above all, for those who seek to get an idea of the methodological pillars on which this current of historical linguistics is based.

Keywords: discourse traditions, history of the Spanish language, history of Brazilian Portuguese, historical linguistics, linguistic change
\end{abstract}

\title{
O. INTRODUCCIÓN
}

La noción de tradición discursiva (TD), desarrollada en el seno de la Romanística germana a finales de los años 80 , ha tenido una repercusión considerable más allá de las fronteras alemanas, fundamentalmente en España, algunos países hispanoamericanos y Brasil, territorios en los que se centra el presente artículo. En él se pasa revista a la recepción de este concepto en las dos tradiciones de investigación lingüística mencionadas —la hispánica y la brasileña-, 
con el propósito de acercar al lector a algunos de los trabajos que se podrían considerar representativos de cómo los historiadores del español y del portugués brasileño han adoptado, en sus pesquisas, tanto la propia noción de TD, como el enfoque con el que esta perspectiva de análisis se acuñó entre los representantes de las llamadas Escuelas de Tubinga y Friburgo ${ }^{1}$.

Tanto en lo concerniente a España e Hispanoamérica como a Brasil, el análisis parte del examen de un conjunto de estudios lingüísticos o filológicos cuya autoría corresponde a historiadores de la lengua y no a teóricos del lenguaje o de la lingüística ${ }^{2}$. En la selección efectuada, se han primado, por una parte, las contribuciones de investigadores con vínculos académicos directos - $\mathrm{y}$ continuados en el tiempo- con los principales representantes de la gestación y posterior desarrollo del marco teórico-metodológico de las TD: Eugenio Coseriu, Brigitte Schlieben-Lange, Peter Koch, Wulf Oesterreicher y Johannes Kabatek. Por otra parte, se ha preferido no tener en cuenta las cada vez más numerosas publicaciones — sobre todo de historia de la lengua española - en las que es posible documentar apariciones del término TD que no cabe considerar más que como absolutamente tangenciales ${ }^{3}$, en la medida en que entre los propósitos de tales trabajos no figuran objetivos de investigación relacionados, bien con la descripción de la génesis y la conformación histórica de determinadas TD y/o de determinados aspectos discursivo-tradicionales en ciertos tipos textuales, bien con la comprobación de en qué medida un determinado fenómeno de cambio lingüístico o un hecho lingüístico particular atestiguado en un estado de lengua pretérito pueda haberse visto propiciado o inhibido por condicionantes de naturaleza discursivo-tradicional.

\footnotetext{
A propósito de esta etiqueta, véanse Renwick (1997) y López Serena (2006a). Sobre la acuñación del concepto de TD por parte de Peter Koch (1987), véase López Serena (2021).

2 El lector interesado en este segundo tipo de perspectiva puede consultar López Serena (2011) o Zamorano Aguilar (2020).

3 Algunas referencias a este tipo de aproximaciones se pueden encontrar en López Serena (2021).
} 
Asimismo quedan fuera del alcance de estas páginas los “estudios [no necesariamente] recientes en los que, sin hacer[se] mención [...] a la expresión tradiciones discursivas, sí se tienen en cuenta éstas" (Guzmán 2006: 87) ${ }^{4}$, bien porque se atienda, por ejemplo, a la "influencia que poseen las estructuras discursivas propias de cada tipo de discurso respecto del valor que adquieren los fenómenos lingüísticos testimoniados en cada uno de los tipos de texto" (Bustos Tovar 2006: 1859), bien porque se tenga "muy claro qué es lo que queremos encontrar y qué es lo que nos podemos encontrar, según el tipo de texto elegido” (Cano Aguilar 2003: 34; véase también Garatea 2016: 58-59). Con todo, conviene dejar constancia de que la excelente acogida que el paradigma de las TD ha encontrado en el mundo iberorrománico no es en absoluto ajena al hecho de que, en este ámbito sociocientífico, en consonancia con el apego a la realidad de los textos propio de la Romanística, "de algún modo siempre se ha sabido y se ha comentado que la variación sintáctica depende en gran medida de la tradición textual, y eso tanto si consideramos el texto en su totalidad como cuando lo diferenciamos internamente" (Kabatek 2012: 91; véase ahora Kabatek 2018, cap. 6) ${ }^{5}$. Este fue el contexto de recepción que sirvió de caldo

\footnotetext{
4 Véase, sin embargo, a este respecto, Cano Aguilar (en prensa a, b).

5 En relación con la coincidencia de intereses entre la investigación sobre TD y la filología tradicional, es interesante la siguiente observación de Garatea (2016: 51-52): “No deja de sorprender la velocidad con que el interés por la oralidad, la escritura y las tradiciones discursivas ha engrosado el número de investigadores dedicados a esos temas en el ámbito de la historia de las lenguas. Aunque no son temas nuevos - es posible reconocerlos en trabajos y reflexiones de ilustres filólogos y lingüistas desde el siglo XIX-su moderna difusión llena el vacío generado por epistemologías y teorías que, durante el siglo XX encerraron el objeto de estudio hasta desvincularlo de la praxis, del hablar, del fondo tradicional de los usos verbales y de la función simbólica inherente a la vida social de cualquier lengua humana. No se trata de volver atrás sino de mirar con nuevos lentes viejos problemas y de renovar las preguntas sobre aspectos esenciales de la competencia lingüística y de la historia de una lengua”. Véase asimismo Garatea (2013b: 40): "La investigación contemporánea cuenta con medios e ideas que permiten recuperar y valorar a los hablantes. En parte, el impulso viene del análisis del discurso, de la sociolingüística y de los acercamientos cognitivos y pragmáticos, pero también de la lingüística de las variedades, de las tradiciones discursivas y, a mi juicio, sobre todo, de un concepto del saber lingüístico no restringido a lo gramatical sino ampliado a un saber que incluye
} 
de cultivo a la exitosa implantación de esta corriente, sobre todo en España, país que contaba con el precedente de la Escuela de Filología fundada por Menéndez Pidal y sabiamente continuada por Rafael Lapesa, de quienes los hispanistas que han tomado el testigo de la investigación sobre TD son, en gran medida, herederos. No en vano, como destaca Carlos Garatea, Menéndez Pidal adelantó una de las ideas clave del paradigma de las TD, cuando afirmó que "el contacto con la escritura se hace efectivo con moldes tradicionales de elaborar discursos escritos", de forma que, "sujeto poco o mucho a estos moldes, el individuo más genial no puede escribir guiado solo por su genialidad, sino encauzado y limitado por la tradición cultural en que él se ha formado y a la cual sirve" (Menéndez Pidal 1951-1956: 63, en Garatea 2012: 95) .

Dado que la primera parte del título de este artículo — “Tradiciones discursivas, historia de la lengua española e historia del portugués brasileño"- quizás pueda hacer suponer que se vaya a encontrar en él una revisión bibliográfica exhaustiva o una presentación cronológica pormenorizada de la difusión del modelo de las TD en España, Hispanoamérica y Brasil, conviene advertir que su tenor se escora, más bien, hacia el contenido del subtítulo: "Fundamentos teóricos, principios metodológicos y aproximaciones descriptivas". Lo que se persigue, en efecto, en estas páginas - que pretenden ser de interés tanto para quienes necesiten informarse sobre las principales referencias que cabe destacar, en los ámbitos regionales acotados para este estudio, en relación con el paradigma

modos tradicionales de usar la lengua, de valorar las expresiones ajenas y de vincularse con el entorno, la cultura y el mundo. Hay que reconocer, sin embargo, que la retórica y la filología ya habian subrayado algunas de esas ideas" (la cursiva es mía).

${ }_{6}$ De acuerdo con este mismo autor, también en Menéndez Pidal se puede encontrar otra idea interesante a este respecto, la de que "[e]l estudio de una lengua limitado a los textos de épocas literarias es incapaz de ilustrar ciertos aspectos de la vida del lenguaje [porque l] literatura nos presenta el idioma, si no fijado, como suele decirse, al menos muy cobibido por la tradición letrada y el becho lingüistico suele aparecer bajo una sola de sus facetas, la escogida por esa tradición” (Menéndez Pidal 1986: 513-516, en Garatea 2012: 97, n. 6; la cursiva es mía). Sobre el valor de la obra de Lapesa para la filología actual, véase Bustos Tovar y Cano (eds.) (2009). Acerca de la actualidad del pensamiento de Menéndez Pidal, véanse Garatea (2005) y Bustos Gisbert/Cano (eds.) (2020). 
de las TD, como, sobre todo, para quienes busquen hacerse una idea acerca de los pilares metodológicos en que se asienta esta corriente que tan fuertemente ha arraigado a uno y otro lado del Atlántico-, es ofrecer una presentación de los principios, métodos y orientaciones que han dado sustento a la investigación sobre TD en España, Hispanoamérica y Brasil. A tal fin, se parte, efectivamente, de la identificación de la presencia, en los trabajos que se han escogido como ejemplo - y que no abarcan, por tanto, la totalidad de la producción científica en este ámbito de los estudios lingüísticos-, de los principios, métodos y orientaciones que vertebran la investigación iberorrománica sobre TD. En consonancia con este objetivo, y teniendo en cuenta que esos principios, métodos y orientaciones son, en gran medida, compartidos por los investigadores hispanófonos y lusófonos, pese a que se contemplan secciones diferenciadas para España $(\mathbb{S} 3.1)$, Hispanoamérica $(\mathbb{S} 3.2)$ y Brasil $(\mathbb{S}$ 3.3), la extensión del epígrafe centrado en los autores brasileños es menor que la de los apartados dedicados a España e Hispanoamérica porque, para evitar reiteraciones innecesarias, en la exposición de las principales orientaciones descriptivas seguidas en estas tres latitudes todo aquello en lo que no hay diferencias destacadas entre las tres regiones se presenta de manera conjunta al hilo de los ejemplos de estudios sobre el español'.

Más allá de esta introducción, el artículo se organiza en tres secciones, en las que se busca dar respuesta, principalmente, a tres cuestiones: (i) cómo se ha interpretado el concepto de TD en la filología hispánica y brasileña ( $(\mathbb{1}$ ), (ii) qué perspectivas de análisis y qué convicciones metodológicas ha implantado o afianzado, en estas tradiciones de investigación, la adopción de la noción de TD $(\mathbb{2}$ ), y (iii) qué tipo de estudios ha propiciado este paradigma de investigación en las tres zonas geográficas en que el modelo de las TD ha encontrado mayor arraigo $(\mathbb{S})$.

De ahí que en $\ 3.1$, por ejemplo, no se remita exclusivamente a bibliografía española. 


\section{La RECEPCión DEL CONCEPTO DE TD EN ESPAÑa, HISPANOAMÉRICA Y BRASIL}

Una de las primeras publicaciones dedicadas, en España, a las TD fue la mesa redonda coordinada por López Serena en el V Congreso Nacional de la Asociación de Jóvenes Investigadores de Historiografía e Historia de la Lengua Española, celebrado en Sevilla en 2005. La idea de organizar este debate surgió de la constatación de que "[l]a cuestión de las tipologías textuales y los géneros o tradiciones discursivas goza[ba] de una creciente popularidad en la lingüística actual”, del reconocimiento de que se trataba de un asunto relativamente novedoso en el ámbito hispánico, así como de la consideración de que la "falta de acuerdo, sintomática de cualquier etapa inaugural de investigación", hacía extraordinariamente "atractiva" esta temática para una mesa redonda (López Serena 2006b: 49).

Entre las cuestiones que salieron a relucir, y que a día de hoy continúan siendo motivo de controversia, destacaba, en primer lugar, el problema de la falta de delimitación clara entre términos como tipo, clase, género y tradición textual/discursivo(a), a los tres primeros de los cuales pasaba revista la contribución de Borreguero (2006). Llamaba asimismo la atención - y no ha dejado de hacerlo en la actualidad - el problema de la sorprendente variabilidad en la formulación de la definición del propio concepto de TD (Sáez 2006: $89)^{8}$. A este respecto, era sintomático el hecho de que en la bibliografía podíamos - y continuamos pudiendo- encontrar tanto un empleo indiferenciado como sinónimos de todos o algunos de estos términos como propuestas que defienden su uso especializado para distintos tipos de unidades de diversos grados de abstracción y/o diferentes ámbitos de aplicación (López Serena 2011, 2021).

\footnotetext{
8 En la aplicación del modelo de las TD que se hace en Brasil, también Longhin (2014: 11) señala el problema de que "[c]omo as própias expressões tradição e discursiva suscitam diferentes interpretações, em varios campos do saber, é natural que surjam polémicas em torno da noção de TD”.
} 
Una de las controversias relativas a la delimitación de la noción de TD aún pendiente de resolución es la discusión en torno al carácter individual o histórico de las TD, es decir, en torno a qué ubicación debería corresponder a las TD en el marco de la tripartición coseriana del lenguaje en los niveles universal, histórico e individual del análisis, establecidos por Coseriu a raíz de su consideración de que "[e]l lenguaje es una actividad humana universal que se realiza individualmente, pero siempre según técnicas históricamente determinadas”; de ahí que “[e]n el lenguaje se pued[a]n, por tanto, distinguir tres niveles: uno universal, otro bistórico y otro individual (Coseriu 1957[19883]: 269; cursivas originales).

\begin{tabular}{|l|l|l|}
\hline $\begin{array}{l}\text { NIVEL } \\
\text { UNIVERSAL }\end{array}$ & $\begin{array}{l}\text { SABER } \\
\text { ELOCUCIONAL }\end{array}$ & $\begin{array}{l}\text { saber hablar en general, de acuerdo con } \\
\text { los principios generales del pensar y con } \\
\text { la experiencia general humana acerca del } \\
\text { mundo }\end{array}$ \\
\hline $\begin{array}{l}\text { NIVEL } \\
\text { HISTÓRICO }\end{array}$ & $\begin{array}{l}\text { SABER } \\
\text { IDIOMÁTICO }\end{array}$ & $\begin{array}{l}\text { saber hablar de acuerdo con las normas } \\
\text { de la lengua que se realiza }\end{array}$ \\
\hline $\begin{array}{l}\text { NIVEL } \\
\text { INDIVIDUAL/ } \\
\text { ACTUAL }\end{array}$ & $\begin{array}{l}\text { SABER } \\
\text { EXPRESIVO }\end{array}$ & $\begin{array}{l}\text { saber hablar en situaciones } \\
\text { determinadas, saber estructurar los } \\
\text { discursos de acuerdo con las normas de } \\
\text { cada uno de sus tipos }\end{array}$ \\
\hline
\end{tabular}

Fig. 1. Los niveles universal, histórico y actual del lenguaje y los saberes elocucional, idiomático y expresivo de acuerdo con la propuesta de Coseriu (1956-57) (véase ahora Coseriu 2019: 32)

Para Koch, las TD son entidades del nivel histórico del lenguaje. Por esta razón, él consideró imprescindible desdoblar este nivel para dar cabida en él tanto a las lenguas y sus variedades diasistemáticas como a las TD: 


\begin{tabular}{|l|l|l|}
\hline NIVEL & DOMINIO & TIPO DE REGLAS \\
\hline universal & actividad del hablar & reglas elocucionales \\
\hline \multirow{2}{*}{ histórico } & lengua histórica particular & reglas idiomáticas \\
\cline { 2 - 3 } & tradición discursiva & reglas discursivas \\
\hline \multirow{2}{*}{ actual/individual } & discurso & \multicolumn{2}{|l}{} \\
\cline { 1 - 2 }
\end{tabular}

Fig. 2. Niveles y dominios de lo lingüístico (Koch 1997: 45; véase también Koch 2008: 54)

Para Kabatek, sin embargo, quien coincide, en este extremo, con Lebsanft $(2005,2006)$, las TD forman parte, más bien, del nivel individual del lenguaje, ya que poseen una naturaleza más próxima al

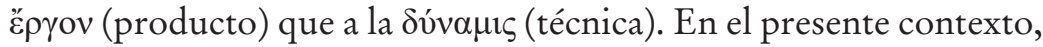
se desiste de abordar este debate, por dos motivos. En primer lugar, porque su examen nos desviaría del análisis de la recepción del paradigma de las TD en España, Hispanoamérica y Brasil, que es el propósito específico de este trabajo. En segundo lugar, porque los historiadores de la lengua, de cuyas aportaciones nos hacemos eco en estas páginas, no manifiestan ningún interés por la distinción entre el carácter individual o histórico de las TD, en el sentido

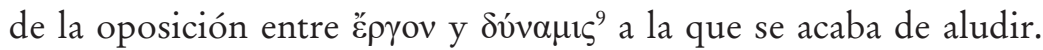
De hecho, lo más habitual es que la mayoría de ellos combine las perspectivas de Koch y de Kabatek sobre las TD obviando que el

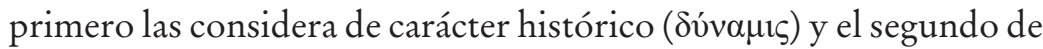
naturaleza individual ("̌́pov). Sirva, como ejemplo de esta postura ecléctica, como decimos generalizada en la lingüística histórica, la siguiente cita extraída de una reciente publicación en portugués, en la que se reproduce la definición de Kabatek (2005a), pero se apostilla, en sintonía con el pensamiento de Koch (1987, 1997, 2008;

\footnotetext{
9 Que Kabatek interprete las TD como categorías del nivel individual no impide que las considere también entidades de naturaleza histórica (véase más abajo la n. 35), ya que, en su opinión, es necesario diferenciar entre la historicidad de las lenguas (primera historicidad o historicidad primaria) y la historicidad de los textos (segunda historicidad). Sobre esta distinción, así como sobre los motivos que parecen subyacer a las discrepancias entre Koch y Kabatek, cuestiones en las que no se entrará en este trabajo, véanse López Serena (2021: $\$ \int S$ y 1, nn. 10 y 11 en preparación).
} 
véase, de nuevo, la fig. 2), que la noción de TD exige reduplicar el nivel histórico:

O conceito de tradição discursiva (TD) é definido, aquí, a partir de um laço que se establece entre actualização e tradição via repetição de um texto, ou de uma maneira particular de escrever ou falar, significável, e, portanto, com valor de signo propriamente dito. Uma TD pode se formar em relação a qualquer finalidade de expressão ou qualquer elemento de contúdo (Kabatek 2005: 159), a partir da reduplicação do nível histórico de Coseriu (LopesDamasio 2019: 189).

Una solución de compromiso similar ofrece también Vázquez Laslop (2018: 162), quien sostiene, de una parte, que la

dinámica de las tradiciones textuales responde a lo esperable a la luz de la teoría de las tradiciones discursivas, específicamente, a lo que Koch $(1997,45)$ ha identificado como la duplicación del nivel histórico de los saberes lingüísticos del modelo coseriano, es decir, por un lado la historicidad del saber idiomático y, por otro lado, la historicidad de los moldes textuales no dependientes del saber idiomático[;]

al tiempo que apostilla, a renglón seguido, que

Kabatek $(2005[\mathrm{c}])^{10}$ ha propuesto llamar a la primera "historicidad primaria", como una primera faceta de la historicidad de la lengua, relativa a la determinación histórica de los hablantes de una comunidad lingüística idiomática, y a la segunda "historicidad secundaria" relativa a la tradición textual, en el sentido de que las configuraciones de los "productos discursivos" se repiten históricamente y se combinan con innovaciones expresivas[;]

sin reparar, en ningún momento, en que la duplicación de Koch es un desdoblamiento del nivel histórico (véanse, de nuevo, las figs. 1 y 2), mientras que la de Kabatek sitúa la primera historicidad,

10 Concretamente remite a Kabatek (2005c: 333-336). 
efectivamente, en el nivel histórico del lenguaje, pero ubica la segunda historicidad en el nivel individual ${ }^{11}$.

Al hilo de la mención a la definición de TD de Kabatek (2005a) que permea las palabras de Lopes-Damasio que se acaban de reproducir, conviene detenerse, siquiera sea brevemente, en señalar qué definiciones han tenido mayor repercusión en el ámbito hispánico y brasileño y qué conclusiones es posible extraer de los resultados que arroja dicha exploración. A este respecto, destaca, en primer lugar, la definición propuesta por Jacob y Kabatek (2001), que, por encontrarse en un libro publicado en español, ha sido, junto con los trabajos de Kabatek (2001, 2005a, 2007) aparecidos también en este idioma (véase ahora Kabatek 2018), extraordinariamente influyente en la difusión, más allá de la filología románica alemana, de esta corriente ${ }^{12}$ (véanse también Kabatek (ed.) 2008, Koch 2008 y Oesterreicher 2001, 2003, 2007, 2011a, 2011b). Jacob y Kabatek introducen el concepto TD tras haberse referido al hecho de que la lingüística contemporánea

11 Tampoco aborda la cuestión de los niveles Garatea (2013b: 47), cuando, apelando a Koch (2008: 55), indica que "la historicidad de las tradiciones discursivas es distinta de la historicidad de las lenguas históricas y que, por ello, debe tenerse en cuenta que son las lenguas históricas o sus variedades las que definen a los grupos o comunidades lingüísticas mientras que son los grupos profesionales o religiosos, las corrientes literarias, los movimientos políticos, la administración, etc., los que definen a las tradiciones discursivas”. En realidad, como señala acertadamente Vázquez Laslop (2014a: 177), la idea de que las tradiciones textuales están ancladas en instituciones o grupos determinados, y que lleva a distinguir entre comunidades textuales y comunidades lingüísticas, la formuló ya Schlieben-Lange (1983: 139): “Die Texttraditionen sind [...] im Textgemeinschaften verankert, in Institutionen z. B. oder in literarischen Gruppen. Daß gelegentlich doch die Textgemeinschaften mit den Sprachgemeinschaften zusammenfallen, ist eine sekundäre Erscheinung” " $L a s$ tradiciones textuales están ancladas en comunidades textuales, por ejemplo en instituciones o grupos literarios. El hecho de que ocasionalmente las comunidades textuales coincidan con comunidades lingüísticas es secundario" (la traducción es mía)].

12 De ella se hace eco tempranamente, por ejemplo, Sáez (2006: 89) y a ella apela asimismo, en idéntica fecha, Pons Rodríguez (2006a: 67), cuando indica que el objetivo de ese trabajo es "observar las implicaciones de [las] [...] tempranas tipologías [efectuadas por la retórica desde la Antigüedad a la Edad Media para el ejercicio práctico de la escritura $[\ldots]$ y [...] mostrar, al tiempo, cómo los [propios] tratados retóricos formaron parte de lo socialmente establecido que se respeta en la producción del discurso (Jacob y Kabatek 2001), es decir, [cómo estos] estaban incrustados en el filtro de la tradición discursiva que condicionaba todo acto comunicativo". 
había empezado a tener en cuenta, junto a "las clásicas «variedades» del diasistema Coseriano (sic)”, también "una tipología de constelaciones discursivas, constituidas por las condiciones pragmáticas de producción y de recepción del lenguaje estudiado”, que permitían distinguir entre "un lenguaje de proximidad y otro de distancia" (Jacob y Kabatek 2001: viii, cursiva original):

Inmediatez

\begin{tabular}{|l|}
\multicolumn{1}{|c|}{ Condiciones } \\
comunicativas \\
a) comunicación privada \\
b) confianza \\
c) emocionalidad \\
d) anclaje en situación y \\
acción comunicativas \\
e) posible referencializa- \\
ción desde aquí y ahora \\
del hablante \\
f) proximidad física \\
g) fuerte cooperación \\
h) carácter dialógico \\
i) espontaneidad \\
j) libertad temática \\
k) etc. \\
\hline \multicolumn{1}{c|}{ Estrategias de } \\
$\quad$ verbalización \\
\hline - contextualización \\
extralingüística, gestual, \\
mímica, etc. \\
- escasa planificación \\
- carácter provisional \\
- sintaxis agregativa \\
- etc. \\
\hline
\end{tabular}

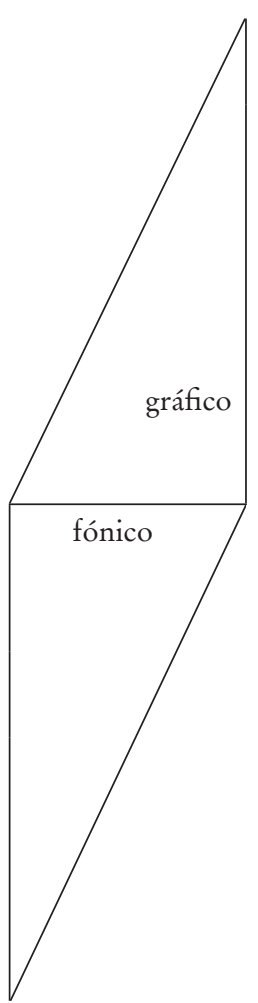

Distancia

\section{Condiciones comunicativas}

a') comunicación pública

b') desconocimiento

c') ninguna emocionalidad

d') independencia de la situación acción comunicativas

e') imposible referencialización desde el aquí y ahora del hablante

f) distancia física

$\left.\mathrm{g}^{\prime}\right)$ débil cooperación

h') carácter monológico

i') reflexión

j') fijación temática

$\left.k^{\prime}\right)$ etc.

\begin{tabular}{|l|}
\hline \multicolumn{1}{|c|}{$\begin{array}{c}\text { Estrategias de } \\
\text { verbalización }\end{array}$} \\
\hline - contextualización \\
lingüística
\end{tabular}

Fig. 3. Parámetros situacionales de la inmediatez y la distancia comunicativa y estrategias de verbalización correspondientes (Koch/Oesterreicher [1990] 2007²:34)

Una vez introducida en la discusión la propuesta de Koch y Oesterreicher $\left(1985,1990\left[2007^{2}\right] / 2011^{3}\right)$ de diferenciar, en el nivel 
universal del lenguaje (véanse, de nuevo, las figs. 1 y 2), entre inmediatez (o proximidad) y distancia comunicativas, tanto desde un punto de vista externo (vinculado con los parámetros situacionales que determinan uno y otro tipo de constelación comunicativa) como desde el punto de vista interno de las estrategias de verbalización que suelen propiciar ambos tipos de situaciones (véase a este respecto la fig. 3), Jacob y Kabatek señalan, para el plano histórico (véase de nuevo la fig. 2), lo siguiente:

A estos modos de comunicación, que se miden en categorías de pragmática universal y que sirven para identificar los rasgos universales propios de cada constelación discursiva, corresponden EN EL PLANO HISTÓRICO las llamadas tradiciones discursivas. Se trata de moldes histórico-normativos, socialmente establecidos que se respetan en la producción del discurso. A través de estas categorías, cada discurso, y de ahí cada texto histórico, no sólo forma parte de una lengua determinada (o de varias lenguas) sino que se sitúa dentro de una filiación intertextual, constituida por una serie de elementos repetitivos, tanto en el plano de los «entornos» (constelaciones situacionales, mediales o institucionales) como en el plano de las formas detectables en la superficie del texto mismo (p. ej. pasajes textuales concretos, carácter formulario, construcción, lengua) (Jacob y Kabatek 2001: viii; cursiva original; la versalita es mía) ${ }^{13}$.

13 También Wulf Oesterreicher partió de estos parámetros situacionales en un artículo de 1997 que no se ha llegado a traducir aún ni al español ni al portugués: "Der Erwerb diskurstraditionellen Wissens zeigt, daß es sich bei Diskurstraditionen um Abstraktionen handelt, die aus ganz bestimmten kommunikativ fundierten Identifizierungs-, Konstantisierungs-, Habitualisierungs- und Legitimierungs-prozessen resultieren. [...] Wir können hiermit [...] Diskurstraditionen bestimmen als konventionalisierte Kristallisationskerne von bestimmten Parameterwerten der oben skizzierten Kommunikationsbedingungen und mehr oder minder strikt vorgeprägten Versprachlichungsanforderungen einerseits sowie von bestimmten gesellschaftlich determinierten inhaltlich-thematischen Wissenskomplexen andererseits" (Oesterreicher 1997: 24; véase también Koch 1997: 56-57). [La adquisición del saber discursivo-tradicional muestra que las tradiciones discursivas son abstracciones que resultan de procesos comunicativos muy específicos de identificación, constatación, habitualización y legitimación. [...] A este respecto, podemos [...] definir las tradiciones discursivas como formas prototípicas convencionalizadas en las que han cristalizado ciertos valores de los parámetros de las condiciones de comunicación descritos anteriormente, así como, por un lado, requisitos de 
Ahora bien, por encima de la propuesta por Jacob y Kabatek (2001), sin duda, la definición de TD más citada tanto en español como en portugués es la formulada por Kabatek $(2005 a)^{14}$ en solitario, de acuerdo con la cual una TD consiste en

la repetición de un texto o de una forma textual o de una manera particular de escribir o de hablar que adquiere valor de signo propio (por lo tanto, es significable). Se puede formar en relación con cualquier finalidad de expresión o con cualquier elemento de contenido cuya repetición establece un lazo entre actualización y tradición, es decir, cualquier relación que se pueda establecer semióticamente entre dos elementos de tradición (actos de enunciación o elementos referenciales) que evocan una determinada forma textual o determinados elementos lingüísticos empleados (Kabatek 2005a: 159; véase ahora también Kabatek 2018: 170).

En relación con la utilidad de esta definición para la lingüística histórica, Álvaro Octavio de Toledo destaca lo siguiente:

Una definición basada en la idea de repetición evocadora y ampliable a elementos o secuencias inferiores al texto e incluso a la oración convierte a las TD, como es fácil de entender, en entidades extraordinariamente atractivas para quien investiga la historia de la lengua, por cuanto le proporcionan una herramienta previamente inexistente para conectar directamente la repetición de un elemento o construcción (su frecuencia, en suma) con una distribución restringida (o, al menos, dominante) en un conjunto de textos interrelacionables según criterios varios (pero no necesariamente dependientes unos de otros, ni en términos genéricos ni de rasgos de género: una constelación textual) (Octavio de Toledo 2018: 119; cursiva original $)^{15}$.

verbalización más o menos estrictamente predefinidos, y, por otro lado, conocimientos socialmente determinados en cuanto a su contenido y temática (la traducción es mía)].

14 Esta es la definición de la que, como decíamos, se hace eco Lopes-Damasio (2019: 189). Véase Kabatek (2006) para la versión en portugués, que, pese a su fecha, se redactó antes que la versión española de 2005, que modifica y actualiza el texto publicado en Brasil un año después.

15 Aunque, por lo general, en relación con la difusión de innovaciones lingüísticas, se acepta que "las diferencias entre géneros discursivos son fundamentalmente en términos 
Para ilustrar con algunos ejemplos concretos, fáciles de comprender, a qué se refiere exactamente Octavio de Toledo cuando dice que uno de los principales atractivos de la noción de TD para el historiador de la lengua estriba en que las TD no se identifican con géneros, sino que pueden reconocerse en la repetición evocadora de elementos o secuencias inferiores al texto e incluso a la oración, nos serviremos de un fenómeno discursivo-tradicional cuya aparición "en el contexto andino de los siglos XVI y XVII" no se puede considerar, de acuerdo con Garatea (2013a: 10), "trivial ni anecdótica". Me refiero a la presencia del conector item, a inicio de párrafo, precedido generalmente por más, que ya fue considerada como un rasgo tradicional de los textos jurídicos por Eberenz (1994) y de cuya localización en textos andinos (véase Garatea 2004, 2006, 2013a) Garatea concluye que "no hace otra cosa que reafirmar que las tradiciones discursivas son parte de la historia del español de América" (Garatea 2013a: 10) ${ }^{16}$.

En esta misma línea, es oportuno traer a colación las siguientes palabras de Lola Pons, que, aunque referidas en su caso específicamente a los textos medievales, resultan metodológicamente extrapolables a la lingüística histórica en general: "los textos medievales se acogen a tipos discursivos que mediatizan fuertemente

de frecuencia de uso y no tanto de presencia o ausencia de una innovación" (Company 2008: 37), en el marco del paradigma de las TD también se ha señalado cómo "una innovación lingüística asociada a una tradición textual llega a convertirse en una nueva regla discursiva y, eventualmente, en una nueva regla idiomática" (véase Gallegos Shibya 2018: 16, quien pone como ejemplo el estudio de Koch (2008) sobre la forma de tratamiento vuestra merced). En el ámbito brasileño, invoca también esta idea Castilho (2011: 278), quien hace referencia a cómo Jungbluth (2005: 11) destaca que "esse nível das tradições discursivas permite a observação de mudanças linguísticas paulatinamente em diferentes géneros textuais até que a língua seja afetada de modo geral”.

16 Otros dos fenómenos discursivo-tradicionales que afloran en elementos inferiores al texto e incluso a la oración, identificados como TD en algunos trabajos recientes, son la presencia de la forma sabed en textos jurídicos mexicanos - téngase presente que en México no se utiliza, en la primera historicidad, la conjugación correspondiente a la segunda forma del plural, ya que la única forma de tratamiento posible es ustedes(véase Vázquez Laslop 2014a: 186) y la del pronombre vosotros — de nuevo, inexistente en la interacción cotidiana en el Cono Sur- en los albores de la prensa uruguaya (véase Bertolotti 2020, así como el epígrafe 3.2, más abajo). 
la formalización de los contenidos en función de una serie de ingredientes implícitos en las rutinas textuales anteriores o explícitos en materiales metatextuales de naturaleza más o menos preceptiva" (Pons Rodríguez 2008: 197). Esto obliga a "entender los textos como híbridos en que convergen y se agregan prácticas discursivas previas" (Pons Rodríguez 2008: 197-198) y conduce a la siguiente constatación:

De nada sirve una clasificación histórica de los textos [...] que los descomponga en categorías herméticas o discretas; tampoco nos valen concepciones de los discursos como constructos monotípicos ${ }^{[17]}$. Si queremos dar cuenta de la relación de la textualidad medieval con el código que le da cuerpo, tenemos que buscar una teoría de la clasificación textual que considere los rasgos lingüísticos y su relación con las condiciones de enunciación, que contemple los discursos como acontecimientos, como objetos sociohistóricos, que considere la relación entre cambios en la historia social y cambios en los tipos de discursos. Esa es la visión que está en la base de la teoría de las TD, que exige la puesta en marcha de mecanismos de relación con otros componentes del discurso debidos también al modelo textual elegido y determinados por la realidad social o institucional, $\mathrm{y}$, en consecuencia, susceptibles de ser modificados o alterados por cualquier cambio de esos parámetros (Pons Rodríguez 2006a: 78) ${ }^{18}$.

La idea, a la que hemos visto que se refiere Pons Rodríguez (2008: 197), de que en los textos conviven elementos que conservan prácticas discursivas de épocas anteriores junto con elementos innovadores es un pilar fundamental de la investigación sobre TD llevada a cabo, en Hispanoamérica, tanto por María Eugenia

\footnotetext{
17 En el rechazo de la consideración de constructos monotípicos insiste también Guzmán (2006: 87): “no [...] faltan trabajos recientes que, aunque mencionan e incluso dicen prestar especial atención a las tradiciones discursivas, no pasan de su mera mención, se basan en adscripciones apresuradas, se concentran en el estudio de elementos de dichas tradiciones cuya relevancia es, cuanto menos, oscura, o comparan textos de diferentes tradiciones como si de estructuras monolíticas se tratara. Resulta claro que con ello, lejos de aportar elementos de interés en torno al objeto de estudio, se crean encasillamientos inútiles y entorpecedores".

18 Prácticamente las mismas palabras se pueden leer en Pons Rodríguez (2008: 221).
} 
Vázquez Laslop como por Carlos Garatea. La primera ha dedicado toda una serie de trabajos (véase a este respecto más abajo \$3.2) a analizar el equilibrio entre conservación e innovación que se observa al examinar, desde un punto de vista lingüístico-discursivo, las transformaciones históricas experimentadas por las diferentes tradiciones jurídicas que se pueden identificar en la historia mexicana desde la época de la conquista a la actualidad. Así, siguiendo a Koch (1997: 59-61) y Wilhelm (2001: 470-472), esta autora sostiene que, de acuerdo con "la teoría de las tradiciones discursivas[,] [...] en momentos de transiciones culturales los cambios textuales no se desarrollan de manera drástica" (Vázquez Laslop 2014a: 176). Más bien al contrario, en su opinión, tal y como sostenía Koch, "las nuevas tradiciones [nunca] [...] surgen ex nibilo, sino que se conforman a partir de algo dado (Koch 1997: 60). De tal manera que los elementos conservadores se mantendrán en los textos, conviviendo con los elementos innovadores, en la medida en que se sigan cumpliendo fines comunicativos determinados" (Vázquez Laslop 2014a: 179). Así las cosas, se generaría una suerte de dinamismo que Peter Koch representó gráficamente tal y como se ve en la figura 4, a continuación, de acuerdo con el cual las TD se irían renovando paulatinamente (y pasarían de A B C D a B C D E y, más tarde, a C D E F), pero siempre sobre la base segura de los aspectos discursivo-tradicionales precedentes:
A B C D
$B$ C D E
C D E F
D E F G
E F G H

Fig. 4. Parecidos de familia entre tipos textuales a lo largo del tiempo

(Koch 1997: 60, citado a partir de Vázquez Laslop 2014a: 179) 
Por su parte, Carlos Garatea destaca, en un trabajo sobre "El español colonial en dos textos andinos (Perú, s. XVI y XVII)”, cómo los Textos de bilingües de los siglos XVI y XVII y los Documentos lingüísticos del Perú. Siglos XVI y XVII, editados por Rivarola en 2000 y 2009, respectivamente, están "llenos de formulismos y tradiciones medievales” (Garatea 2013a: 2); de ahí que considere “indispensable asumir las consecuencias que ocasiona el hecho de que la difusión del español en América también sea la difusión de textos y de patrones de elaboración con una larga historia de uso y de cambios” (Garatea 2013a: 5, n. 4) y que defienda que “[s]ólo prestando atención a las tradiciones textuales y a los patrones exigidos por ellas es posible distinguir en un corpus aquello que es una innovación, un efecto del contacto, una muestra de la creatividad del autor o la evidencia de la continuidad de un modelo" (Garatea 2013a: 5, n. 5) ${ }^{19}$. En esta misma línea, en relación con las dificultades de rastrear la presencia de la lengua oral en los textos, Garatea advierte también sobre cómo, en todo caso,

El paso de lo oral a lo escrito implica la distorsión [...] [o] el reacomodo del discurso a otras condiciones y requerimientos de la enunciación [...]. Por ello es tan importante avanzar hacia una tipología de los textos que llegaron a América y de sus respectivas características formales ${ }^{20}$, una tipología que ayudará tanto al contraste como en determinar el estatus y la función de los hechos de lengua (Garatea 2013b: 51).

El interés por la presencia de lo oral en lo escrito y por el rastreo de las relaciones de intertextualidad a que da lugar la filiación discursivo-tradicional derivada de la repetición de formas textuales vinculadas con determinadas constelaciones situacionales, mediales o institucionales de la que hablan las dos definiciones de TD que

19 Como este mismo especialista pone de relieve: "En el estudio, los textos saltan a los ojos como una tupida red de relaciones y vínculos que hay que desmontar para distinguir las novedades de aquello que no es más que simple continuidad cultural o mera tradición” (Garatea 2013a: 15).

20 En nota: "En esta línea, están los estudios y las propuestas de Wesch (1994, 1998, 2005 y 2006)". 
mayor impacto han tenido más allá de las fronteras geográficas de Alemania - y cuya presencia acabamos de documentar en la recepción de este enfoque fuera de la Romanística germana- es patente en la bibliografía escrita en español y portugués. Por lo que se refiere a España, por un lado, la vinculación entre la preocupación por las TD y el deseo de atender, en la descripción histórica, en la medida en que esto sea posible, al espectro completo de las formas textuales características tanto de la inmediatez como de la distancia comunicativa a las que se refieren Jacob y Kabatek (2001) puede ayudarnos a entender por qué el concepto de TD ha encontrado tan buen acomodo en la lingüística histórica hispánica, en la que una pléyade importante de estudiosos se ha interesado por el análisis de las huellas de lo oral en lo escrito ${ }^{21} \mathrm{y}$, por tanto, por la tensión entre el polo de la oralidad o máxima inmediatez comunicativa y el polo de la escrituralidad o máxima distancia comunicativa. Por otro lado, en la acogida, entre los historiadores de la lengua española, del marbete TD como alternativa a los de género textual o discursivo parece haber desempeñado un papel fundamental el hecho de que los lingüistas hispanófonos han considerado, de manera general, el término género más bien propio de los estudios literarios ${ }^{22}$. A este

21 Para una primera aproximación a las referencias bibliográficas más importantes en este ámbito, que Del Rey (2019) clasifica en estudios de oralidad en lo escrito frente a estudios de mimesis de la oralidad, véase López Serena/Sáez Rivera (2018, $\mathbb{S} 0$ ). Con respecto a los fundamentos teóricos y metodológicos del estudio de la escritura de impronta oral en uno de los primeros proyectos dirigidos por Wulf Oesterreicher, véase Renwick (1997). Sobre la importancia de esta línea de investigación en la historia del portugués brasileño, véase, por ejemplo, Longhin-Thomazi y Rodrigues (2013) o Simões (2017: 684), que enuncia como “[u]m dos objetivos básicos” del PHPB “ao reconstituir a história do português brasileiro [...] analizando documentos escritos que ofreçam uma maior proximidade com o vernáculo ou com os falares cotidianos”.

22 Pese a los reiterados alegatos sobre el hecho de que la noción de TD es más amplia que la de género textual o discursivo, en tanto que todo género es una TD, pero no toda TD es género (Oesterreicher 2008; véase también, por ejemplo, Longhin 2014: 23), tanto en España como en Brasil las publicaciones de lingüística histórica intercambian los términos género y tradición discursiva de manera continua (se pueden ver algunos ejemplos en López Serena 2021). Dentro del ámbito brasileño, esto se justifica por la "proximidade entre o modelo de TD e o conceito de gênero discursivo, de Bakhtin" (Longhin 2014: 46), manifiesta en consideraciones como la de que "[a] mundança de 
respecto, Pons Rodríguez (2006a) — quien remite, en este punto, a González Bedoya (1988)—indica:

en los siglos XVIII y XIX el racionalismo y el empirismo redujeron la retórica a una dialéctica, y a un manual de estilo, o sea, al Libro III de Aristóteles. Esta reducción de la retórica hacia el hecho literario explica la historia y el bloqueo referencial del término género literario, hoy utilizado en Teoría de la Literatura pero inhabilitado para los estudios de Lingüística de la comunicación (Pons Rodríguez 2006a: 72-73).

En este mismo sentido, el propio Wulf Oesterreicher no tuvo reparos en aclarar que él prefería hablar de TD y no de géneros textuales o tipos de textos, “[e]n primer lugar, para enfatizar la dinámica interna de estos modelos discursivos históricos ${ }^{23}$ ”, pero, “en segundo lugar, para evitar la identificación con una teoría literaria de los géneros” (Oesterreicher 2012: 231-232) 24.

Por lo que respecta a la aplicación del concepto de TD al ámbito geográfico americano, junto al posible influjo ejercido por la propia aceptación de este enfoque entre los historiadores de la lengua española europeos, hay que mencionar la importancia del trabajo realizado por hispanistas o lusitanistas latinoamericanos que se han formado directamente en Alemania. Así, para los estudios del español en América, son fundamentales las investigaciones de Martha Guzmán sobre el español del Caribe durante el periodo colonial (véase Guzmán 2006, 2007, 2008, 2018); de Carlos Garatea sobre los primeros documentos de quechua hablantes bilingües

\footnotetext{
uma TD se concretiza como producto de uma convivencia, que pode ser mais ou menos duradera, entre os elementos convencionais e os elementos innovadores da TD, gerando situações de mescla, situações de derivação entre TD”.

23 Véanse más abajo el epígrafe 2 y la n. 35.

${ }^{24}$ En este mismo pasaje, Oesterreicher añade otras dos razones más, que ya hemos mencionado más arriba y sobre las que volveremos enseguida: “en tercer lugar, para distanciarnos de los intereses y procedimientos puramente clasificatorios de la llamada tipología textual” y "en cuarto lugar, porque las tradiciones discursivas no se corresponden necesariamente con modelos textuales enteros, sino que pueden ser caracterizadas también por ciertos rastos lingüístico-estilíticos que se emplean en diferentes géneros de perfil concepcional comparable”.
} 
(véase Garatea 2004, 2006, 2012, 2013a, 2013b, 2016); o de Alfonso Gallegos Shibya $(2003,2011,2018,2020)$ y María Eugenia Vázquez Laslop (2014a, 2014b, 2015, 2018, 2019a, 2019b) sobre el español de México ${ }^{25}$. Más recientemente, en Uruguay (véase, por ejemplo, Bertolotti y Coll, coords. 2020), y probablemente a consecuencia de la importancia que el Corpus diacrónico y diatópico del español de América (CORDIAM) concede a la "diversidad tipológica textual" (véase Bertolotti y Company 2018: 76, 83-92), se ha puesto en marcha un proyecto de investigación sobre "Lengua y prensa en el Uruguay del siglo XIX" que presta una atención especial a las TD en el abordaje de estos textos como fuentes para la historia de la lengua.

Por último, en lo que concierne a Brasil (véase $\mathbb{3} 3$ ), la influencia de la tutela ejercida por Johannes Kabatek es evidente en las investigaciones de José da Silva Simões (2007, 2020), Aurea Zavam (2009), Sanderléia Longhin (2014), Célia Lopes (2011) o Alessandra Castilho da Costa (2010, 2011, 2015, 2020). El primero de estos lingüistas, José Simões, es el autor de la versión portuguesa de Kabatek (2005b), y corrigió también, antes de su publicación, el texto en portugués de Kabatek (2006), mientras que la última, Alessandra Castilho da Costa, es la responsable de la recentísima versión portuguesa del artículo fundacional de Peter Koch (1997) sobre TD (véase Koch 2021).

25 La cubana Guzmán y el mexicano Gallegos Shibya fueron, como el peruano Carlos Garatea, discípulos directos de Wulf Oesterreicher. Sin embargo, mientras que Guzmán y Gallegos se han dedicado, preferentemente, a la historia de la lengua, el ámbito de especialización de Garatea, que fue uno de los autores que participaron en el volumen sobre TD editado por Jacob y Kabatek en 2001, ha sido fundamentalmente el de la historiografía; de ahí que en esa obra colectiva dedicara su contribución (Garatea 2001) a la "Variedad de tradiciones discursivas en Orígenes del español de Menéndez Pidal" (véase, sin embargo, Garatea 2004, 2006, 2012, 2013a, 2013b, 2016). Por su parte, la también mexicana Vázquez Laslop fue investigadora visitante en la Universidad de Tübingen, gracias a una beca de la Fundación von Humboldt avalada por el profesor Johannes Kabatek, en el año 2012. 


\section{LA ADOPCIÓN DE LA NOCIÓN DE TD COMO HERRAMIENTA HEURÍSTICA EN LA HISTORIA DE LAS LENGUAS ESPAÑOLA Y PORTUGUESA}

Si volvemos, de nuevo, la mirada hacia la mesa redonda sobre TD a la que se aludió al principio de $\mathbb{S} 1$, nos daremos cuenta de que una de las cosas que más importaba a los historiadores de la lengua que participaron en ese debate era hacer ver a los lingüistas de orientación formalista, defensores del establecimiento de tipologías discursivas derivadas de directrices teóricas prefijadas, que la predilección de los lingüistas históricos por el concepto de TD se debía, entre otras razones, al rechazo hacia ese tipo de categorizaciones apriorísticas y de vocación universalista ${ }^{26}$. En este sentido, es sumamente interesante la siguiente afirmación de Octavio de Toledo:

Si las TD se avienen mal con las tipologías clasificadoras, es evidente su utilidad, en cambio, para dar cuenta de las convergencias e hibridaciones entre (clases de) textos que con frecuencia se encuentran en el origen de la cristalización de nuevos géneros a lo largo de la historia. Para el investigador diacrónico, pues, una parte no desdeñable de la utilidad descriptiva de las TD reside en la capacidad de asociar a través de ellas, mediante semejanzas de forma o contenido, géneros (o subgéneros, o macrogéneros) no necesariamente emparentados de forma genética ni pertenecientes al mismo taxón, sino conectados mediante redes de "parecido de familia"[27], cuyos miembros solo necesitan poseer al menos un rasgo común con aquellos a los que se encuentran inmediatamente asociados. Ello permite un acceso intuitivo a las asociaciones entre géneros de innegable potencial heurístico, especialmente en perspectiva histórica (Octavio de Toledo 2018: 119, n. 36).

En la perspectiva histórica, difícilmente se puede recurrir a las propuestas tipologistas, no solo porque los textos que interesan en historia de la lengua se avengan mal con las taxonomías rígidas

\footnotetext{
26 Véase la n. 24 más arriba.

27 Véase de nuevo la fig. 4.
} 
o monotípicas de la lingüística textual formalista ${ }^{28}$, sino porque, como señala Pons Rodríguez (2006a: 70), los defensores de este tipo de aproximación han ignorado sistemáticamente los tipos textuales de épocas pasadas, hasta el punto de que uno de los motivos por el que los historiadores de la lengua abrazaron con entusiasmo el modelo de las TD fue el hecho de que, en opinión de esta investigadora, este vino a cubrir el hueco, denunciado por Marimón (2005: 1022), que suponía "la casi total ausencia de estudios históricos en la investigación sobre tipos de textos”. No extraña, pues, que, cuando Pons se refiere a la escasez de categorizaciones textuales aplicadas a la diacronía, mencione como excepción la clasificación de muestras de escrituralización en lenguas románicas hecha, precisamente, por Peter Koch (1993).

Como se desprende de las palabras de Octavio de Toledo (2018) y Pons Rodríguez (2006a) que se acaban de traer a colación, la buena sintonía entre los historiadores de la lengua española y el paradigma de las TD parece motivada no por cuestiones teóricas relativas a la definición inequívoca de este concepto, a su ubicación bien en el nivel individual, bien en el nivel histórico del lenguaje $\mathrm{e}^{29}$, o a su rigurosa delimitación frente a otras categorías alternativas, sino por la utilidad de esta noción como herramienta heurística ${ }^{30}$; de ahí que en estas páginas se dé preferencia a la cuestión de qué perspectivas de análisis y qué convicciones metodológicas ha introducido o afianzado, en la filología española y brasileña, la adopción de la noción

\footnotetext{
28 Véanse más arriba $\$ 1$ y n. 17.

29 Véanse más arriba $\$ 1$ y n. 9.

30 En el ámbito de la semántica diacrónica del portugués brasileño, en relación con el potencial heurístico de las TD — que entiende como tipos de texto-, Ilari (2020: 83) señala lo siguiente: "Um saldo positivo de asociar as resistencias ao novo, bem como as inovações e os empréstimos a determinados tipos de textos é que o estudo da mudança semántica passa a contar com una beurística que formula preguntas não só para grandes períodos da história social, mas também para tradições discursivas específicas, que assim podem ser usadas como pistas, abrindo una terceira via entre uma história semántica voltada para grandes campos temáticos e uma história semántica que procura atestar e datar individualmente o aparecimiento de novos sentidos" (la cursiva es mía).
} 
de TD, por encima de la pregunta por cómo se ha interpretado, en esta tradiciones de investigación, el concepto de TD.

La desestimación de las categorizaciones in vitro de los enfoques tipologistas y la resistencia a adscribir los productos textuales sometidos a examen por parte del historiador a clases preestablecidas va acompañada, entre quienes abrazan la corriente de las TD, por el reconocimiento de que " $[\mathrm{a}]$ relação entre TD e língua histórica é de interdependencia mútua, pois, de um lado, as TD determinan a escolha de variedades e de formas linguísticas, e, de outro, arranjos linguísticos particulares são típicos e caracterizadores de determinadas TD” (Longhin 2014: 21) ${ }^{31}$, así como por la voluntad decidida de partir desde los textos y de describir, en cada testimonio particular, todos los aspectos discursivo-tradicionales que sea posible identificar. Y es que, como señala Kabatek (2015: 52; la traducción es mía), “[s]i abordamos un texto no a partir de una categorización preestablecida y sin querer adscribirlo a una u otra categoría, sino pretendiendo determinar el alcance completo de las relaciones de tradicionalidad que se manifiestan en ese texto partiendo del propio texto, encontraremos una larga lista, en principio abierta, de aspectos tradicionales”. Pues bien, la adopción firme de esta perspectiva que rehúye las categorías teóricas apriorísticas ${ }^{32}$ está también en el origen de la adopción, entre los historiadores de la lengua, de la noción de TD como herramienta heurística que invoca en relación con una convicción metodológica firmemente arraigada en la filología: la de la necesidad de llevar a cabo una recontextualización (véase Oesterreicher 2001, 2003) de todos los documentos que interese estudiar, para lo cual es necesario prestar atención a la complejidad del contexto histórico, social y cultural en el que tales textos fueron originados y en el marco del cual es obligado interpretar cada uno de

\footnotetext{
31 Veáse más abajo la n. 53.

32 Perspectiva que, en López Serena (2021), en consonancia con la distinción establecida por Fernández Pérez (1993: 213-215; 1999: 23) entre materia y objeto de estudio, se denomina de materia, por contraposición con la perspectiva de objeto de estudio o perspectiva de naturaleza teórica.
} 
los datos lingüísticos que proporcionen ${ }^{33}$. A este respecto, Guzmán (2006: 86) se muestra taxativa: "La relevancia para el análisis lingüístico de la orientación pragmática y de las condiciones de producción y recepción de cada texto y los errores a los que puede llevarnos su desatención no necesita ser señalada" ${ }^{34}$. Efectivamente, a las razones, ya esgrimidas, en relación con la preferencia, entre los historiadores de la lengua, por la noción de TD -en detrimento de términos como género o tipo de texto- se debe sumar también la consideración del carácter explícitamente histórico que, de acuerdo con SchliebenLange, Koch y Oesterreicher tienen las TD ${ }^{35}$. Como señala la propia Martha Guzmán (2006: 81), "[e]sta perspectiva de estudio no aspira a la clasificación de modelos [de construcción del discurso] estrictamente delimitados y mucho menos de validez universal. Sí concede especial importancia a la historicidad de los modelos, a su relación con el contexto histórico y a los procesos de conformación y evolución de dichos modelos". En la misma línea, la investigadora brasileña

33 Para Garatea (2013b: 41), la idea de recontextualización entronca "con algo que la tradición filológica mantuvo como principio: la integración de datos, ideas y fuentes que, con el debido cuidado y rigor analíticos, ayudan a comprender, describir y explicar un texto, un hecho de cultura. De acuerdo con Auerbach (1950) $)^{[\cdots]}$, la premisa que conduce al filólogo es más o menos así: todo texto está culturalmente situado y es portador de dimensiones que se entrecruzan y sobreponen”. En la lingüística brasileña, hay autores como Ilari (2020) que, cuando se refieren a la imposibilidad de interpretar los textos del pasado proyectando sobre ellos categorías del presente, lo hacen mediante una metáfora de acuerdo con la cual las miradas anacrónicas y, por tanto, inadecuadas hacia esos textos provocan "ruidos" que ponen en peligro la realización de una comprensión verdaderamente recontextualizada.

34 Véase en este mismo sentido Castilho (2015: 286): “nenhum fato linguístico é um «fato bruto» (véase Koch 1997: 59) - é sempre um fato linguístico que se apresenta em distorção discursivo-tradicional, que não ocorre sem motivação textual”.

35 Así, de acuerdo con Kabatek (2001: 98-99, n. 5): “El término tradiciones discursivas abarca una amplia gama de fenómenos. Se trata de un término generalizante para todos los elementos históricos designables y relacionables con un texto: textos particulares como actos individuales e irrepetibles, ciertos tipos fundamentales de enunciación (o actos de habla), ciertas formas textuales y determinadas constelaciones de actuación y de entornos)" (la cursiva es mía). Asimismo, de acuerdo con Oesterreicher (2007: 114), las TD se deben entender como "cristalización histórica de finalidades semántico-pragmáticas, de las condiciones comunicativas y estrategias de verbalización” (la cursiva es mía; véase también Pons Rodríguez 2010a: 82). 
Sanderléia Longhin, en sintonía con la concepción coseriana de las lenguas como un continuo hacerse y con la provocación que suponía enunciar, a resultas de esta visión, que el cambio lingüístico no existe (Coseriu 1983), señala:

Assim como as línguas históricas não são conjuntos fixos de técnicas, mas se fazem e se transformam continuamente, os modelos linguísticos tradicionais, as TD, também mostram instabilidade no tempo. São sensíveis às alterações sociais e culturais. Desse modo, nem a língua histórica, nem a TD são productos prontos e acabados, mas na natureza de ambas está o fazimento constante (Longhin 2014: 21; cursiva original).

Por supuesto, la adopción, entre los historiadores de las lenguas española y portuguesa, del concepto de TD, por razones - insisto en ello- de índole metodológica más que teórica (véase a este respecto López Serena 2021) ${ }^{36}$, se vincula también con el deseo de superar la concepción lineal de la evolución lingüística ${ }^{37}$ y está, por tanto, en consonancia con la convicción de que no es posible describir la gramática de un estado de lengua o un proceso cualquiera de cambio lingüístico sin hacer referencia a las TD en que se enmarcan

\footnotetext{
36 Véase, en este sentido, el título de Oesterreicher (2011a): “Conquistas metodológicas en la lingüística diacrónica actual...”, así como Gallegos Shibya (2018: 16), quien remite, a este respecto, a Koch (2008: 80): “el concepto de 'tradiciones discursivas' conlleva importantes consecuencias METODOLÓGICAS en ámbitos como la lingüística variacional, diacrónica, de corpus, etc., y resulta esencial para una descripción más exhaustiva de la microscopia y macroscopia de la evolución de una lengua" (cursiva original; la versalita es mía). Véase también Company (2008).

37 Véase Longhin (2014: 49): “parece um equívoco acreditar que podemos fazer uma diacronia por meio da seleção de textos de mesma TD ou gênero em uma sucessão de sincronias. Nesse caso, enfrentamos o risco de descrever a história de uma TD e não fatos da história da língua”. También Garatea (2016: 55): "la consideración de las tradiciones [...] ayuda a valorar los datos registrados en la documentación y vacuna contra la tentación de encontrar a como dé lugar procesos generales, saltos intercontinentales o evoluciones intrasistemáticas, que muchas veces imponen homogeneidades, cuando de por medio no hay una sino varias historias desarrollándose en simultáneo con la misma lengua” y Garatea (2016: 62): “La realidad es más inasible y menos clara que los objetos modelados y creados con fines científicos. La búsqueda de fenómenos históricos exige determinar el estatus de lo que traen los textos. Que no hablan, ni son fotos, ni responden a proyecciones lineales".
} 
los datos lingüísticos a los que se atiende. La idea, enunciada por Kabatek (2001: 97), es la de atender a la constatación de que "ciertos fenómenos textuales parecen perturbar la verdadera diacronía” (Pons Rodríguez 2006b: 1571; Pons Rodríguez 2007: 278). En esta línea, de nuevo Lola Pons (2006a: 69) destaca cómo "[l]os textos deben su lengua no sólo a una época y a un autor, [sino] también a las posibilidades y obligaciones lingüísticas que provenían de la elección de una forma discursiva y de las instrucciones que sobre esas formas discursivas se contenían en las retóricas" ${ }^{38}$.

\section{Estudios}

\subsection{España}

Los historiadores de la lengua española afines a los principios metodológicos del paradigma de las TD destacan, fundamentalmente, por tres tipos de estudios. Un primer conjunto de aproximaciones se interesa por el análisis de las diferencias lingüísticas que emergen entre textos que han sido producto de la refacción de algún modelo anterior y su(s) respectivo(s) modelos, y que se deban al hecho de que en esta relación intertextual el modelo y sus refacciones posteriores no compartan una misma orientación discursivo-tradicional. Como ejemplo de este tipo de acercamiento pueden servir los estudios que Octavio de Toledo $(2011,2017)$ dedica a identificar variantes textuales morfosintácticas motivadas por factores de tradicionalidad en textos de Teresa de Jesús y Juan de Mena, así como la contribución de Pons Rodríguez a la mesa redonda que se mencionó al principio de $\mathbb{S} 1$. En las páginas finales de ese trabajo, esta autora compara el testimonio que de la vida de santa Marta

\footnotetext{
38 Y aduce: "Sólo la relativa novedad de la teoría de las [...] TD explica que hasta ahora apenas se haya ligado el ars retorica con esta idea de la TD como parte del filtro por el que pasa todo acto comunicativo", idea que ella considera fundamental para estudiar "la historicidad del idioma, la historicidad de los modelos textuales que se eligen para la comunicación y, dentro de ella, la historicidad de los códigos que ordenan esos modelos textuales, funcionando como verdaderos catalizadores del discurso" (Pons Rodríguez 2006a: 69).
} 
ofrece uno de los manuscritos de la Legenda Aurea que se conserva en el Escorial con la versión hecha sobre la vida de esta santa por Álvaro de Luna en Virtuosas e claras mujeres (1446). Al hilo de este ejercicio, Pons interpreta la conversión de oratio perpetua en estilo periódico que identifica en su cotejo como un conjunto de cambios ocasionados por "la distinta tradición discursiva a la que pertenecen ambos textos” (Pons Rodríguez 2006a: 77). Finalmente, desde un enfoque traductológico, se puede consultar también la aportación de Del Rey (2016), en la que se analizan diferentes versiones de las Heroidas de Ovidio realizadas entre la Edad Media y el siglo XVII ofreciendo datos sobre las distintas variantes sintácticas que cabe reconocer en este recorrido diacrónico y describiendo la evolución de diversas estrategias discursivo-tradicionales en el contexto de comparabilidad idóneo que proporcionan los textos meta procedentes de un mismo texto fuente.

Un segundo conjunto de estudios se inspira en la formulación, en cierta medida programática, de Jacob y Kabatek (2001: viii), de acuerdo con la cual el "concepto de «tradiciones discursivas» puede considerarse como un eslabón entre la lingüística llamada «externa» y la «interna»"39, que "permite focalizar la lengua histórica como unidad y espacio cultural, mediante el concepto de elaboración lingüística (Sprachausbau)” (cursiva original). A este respecto, cabe destacar que bajo el paraguas de la investigación sobre TD han aflorado, efectivamente, análisis de procesos de elaboración lingüística o de construcciones lingüísticas emanadas de tales procesos, que, por oposición con respecto a las innovaciones debidas a la expresividad, consideradas cambios "desde abajo", se han interpretado como cambios "desde arriba"

39 Sobre los antecedentes filológicos de esta idea, interesa la siguiente observación de Garatea (2013b: 42): "la comprensión del detalle en función del todo, el lazo de lo interno con lo externo y viceversa, permitió que Diez postulara el concepto de lenguas romances a partir de un sustrato del latín vulgar apenas reconocible (Spitzer 1955[1982], 34-35) y, dada la utilidad de este principio, Grimm recomendaba un «Andacht zum kleinen» o una cariñosa atención a lo pequeño”.

40 Véase Del Rey Quesada (2015) para el concepto de contraelaboración, mediante el cual explica cómo una lengua anclada en el ámbito de la distancia comunicativa como el latín 


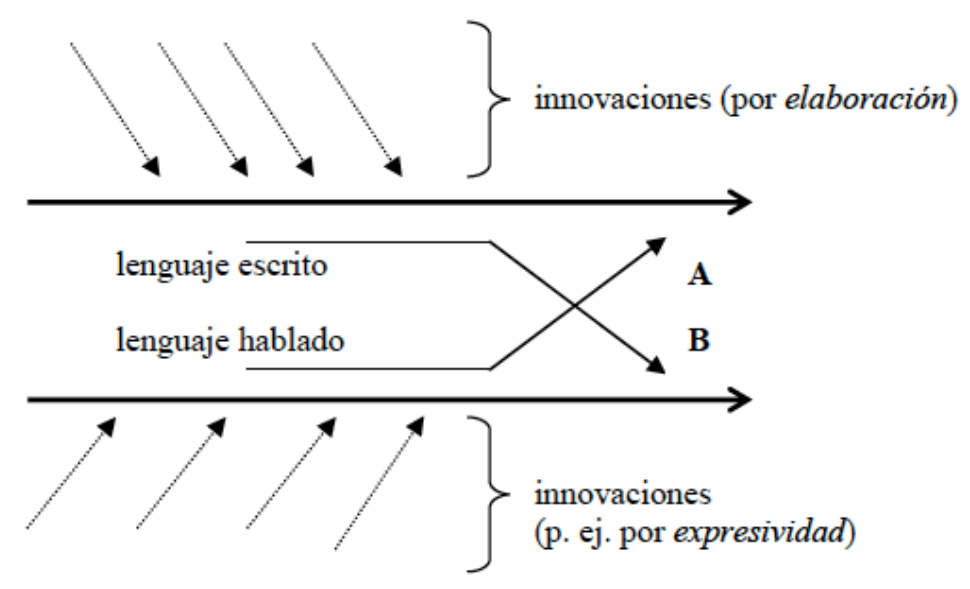

Fig. 5. Cambios por elaboración vs. cambios por expresividad (Jacob y Kabatek 2001)

En esta línea, ya en el volumen editado por Jacob y Kabatek, la indagación, por parte de Mónica Castillo (2001), de formas léxicas y sintácticas que se hubieran empleado en la lengua medieval para expresar la noción de 'excepción' tenía en cuenta tanto innovaciones procedentes "de abajo", atribuidas a la expresividad característica del dominio oral informal, como innovaciones por elaboración surgidas en los textos legislativos y protagonizadas por la recuperación tardía de formas latinas. En este mismo sentido, cabe mencionar algunos trabajos de Lola Pons en que se recurre al concepto de TD para dar cuenta de la historia de determinadas unidades lingüísticas de nuestro idioma. Así, por ejemplo, en Pons Rodríguez (2007) se considera que la paulatina implantación de el cual en castellano supuso

\footnotetext{
humanista desarrolla, a partir de modelos más antiguos, estrategias lingüísticas típicas de la oralidad concepcional. En un reciente trabajo (Del Rey 2021: $\$ 4.1$ ), el autor aboga por una visión abarcadora del concepto de elaboración lingüística, que subsuma no solo los procesos de elaboración que implican un movimiento de "arriba abajo", sino también "de arriba arriba" y "de abajo arriba", siempre que el resultado de dicho movimiento repercuta en la variedad estándar o en el ámbito de la distancia comunicativa de una lengua.
} 
un ejemplo de progreso en la elaboración lingüística intensiva del idioma (Ausbau en el aparato teórico de Kloss 1952[1978]; 1967) a la búsqueda de una mayor distancia comunicativa [...] [que] se construye mediante el préstamo de una estructura de los textos a los textos, un cambio desde arriba [...] cuyo factor agente estuvo en el intento de elaboración en romance de una nueva lengua del derecho (fueros, Partidas) y que traspasó la tradición discursiva que lo adoptó desde la esfera jurídica latina (Pons Rodríguez 2007: 297).

De hecho, tal como indica, en el mismo sitio, esta autora, ya en el propio latín, "tras la etapa del latín clásico, esta estructura estaba sometida fuertemente a un condicionante de tradición discursiva: aparecía sobre todo en tipos textuales jurídicos, donde respondía a un deseo de claridad y desambiguación”. Asimismo, en Pons Rodríguez (2010a), donde se analiza “cómo varían el prestigio y la marcación de los adverbios originalmente bajolatinos inclusive, exclusive y respective, a partir de que trascienden sus tradiciones discursivas y su lengua particular de partida" (Pons Rodríguez 2010a: 82 $]^{41}$, se afirma que “[e]l modelo lingüístico del latín técnicojurídico fue, sin duda, un estímulo para que se produjeran trasvases entre similares tradiciones discursivas (TD) de lenguas distintas” (Pons Rodríguez 2010a: 82) (2. $^{4}$

\footnotetext{
${ }^{41}$ Trabajo en que se citan, "como ilustrativos de [la] aplicación del modelo de las Tradiciones Discursivas a la difusión de cambios por gramaticalización” (Pons Rodríguez 2010a: 82, n. 2), los estudios de Girón Alconchel (2008), Octavio de Toledo (2006) y Pons Bordería (2008).

42 En los primeros documentos del español peruano debidos a hablantes bilingües de quechua y castellano, Garatea (2012: 103; 2013a: 11; 2013b: 43-44) señala algunos trasvases desde los textos jurídicos a géneros narrativos como las crónicas. Véase también Octavio de Toledo $(2008,2014,2016)$ como muestras de estudios en los que se atiende a la emergencia y/o difusión de ciertos cambios morfosintácticos, bien en el ámbito de la inmediatez, bien en el de la distancia, y se desarrolla la idea de que, aparte de TD distantes e inmediatas, es necesario contemplar la existencia de "tradiciones medias". De esta noción se vale asimismo Del Rey (2019). Un ejemplo de cómo se tienen en cuenta los condicionantes discursivos en el rastreo del proceso de gramaticalización del organizador de la materia discursiva con tanto, hoy ya desaparecido, ofrece Fernández Alcaide (2008). En este sentido, es interesante que en España algunos autores hablen, para muchos marcadores del discurso, de "gramaticalización por tradiciones discursivas" (véanse Pons Bordería 2008, Estellés 2011, Garrido Martín 2015).
} 
Por último, algunos autores se han interesado por el examen de los cambios experimentados, a lo largo de la historia, por los tipos textuales característicos de unas y otras épocas. Así, además de en relación con la lengua medieval ${ }^{43} \mathrm{y}$ con el español que se desarrolla en América (véase $\$ 3.2$ ), la noción de TD ha tenido también una excelente acogida en los trabajos, cada vez más numerosos, que se dedican al español europeo moderno (véanse, por ejemplo, Octavio de Toledo 2019 y 2020; Carmona Yanes 2019). Como señala L. Pons, en los últimos años, la lingüística histórica hispánica ha logrado "romper el tradicional cierre de los estudios de diacronía en el siglo XVII" y ha puesto de relieve los "numerosos cambios que tuvieron lugar en la estructuración discursiva y la construcción textual durante los siglos XVIII y XIX”, en relación con los cuales ha destacado la posible influencia que en tales cambios pudo tener "la aparición en escena de nuevos tipos de texto, nuevas tradiciones discursivas $^{[\ldots]}$ en las que se exploraron mecanismos diversos de elaboración lingüística: la nueva lengua del periodismo, el nuevo ensayismo, los proyectistas, etc." (Pons Rodríguez 2007: 278) ${ }^{44}$. Entre los tipos textuales y géneros surgidos en esta época destacan, en efecto, los derivados de la aparición de la prensa. Algunos, como los de carácter informativo, hunden sus raíces en tradiciones anteriores, como las relaciones de sucesos estudiadas por E. Méndez y E. Leal (2012: 78), quienes, basándose en las propuestas de Kabatek (2001, 2005a y 2007), abrazan explícitamente el paradigma de las TD, con el que coinciden en que no es posible "entender los

43 A los trabajos dedicados por Lola Pons a esa época desde la óptica de las TD, se une ahora la monografía de Del Rey (2021) sobre los grupos paratácticos como fenómeno discursivo-tradicional en latín y en varias lenguas romances medievales.

${ }^{44}$ En el mismo sentido, Garachana (2014: 964) llama la atención sobre cómo "el enriquecimiento del repertorio de los marcadores discursivos que se localiza en los siglos XVIII y XIX (ver Pons Rodríguez 2010b, 573 y ss. y 2014) no puede desligarse del desarrollo de nuevas formas textuales: el texto ensayístico, que crece notablemente a raíz de la obra de la Ilustración, y la novela larga, que nace con la novela romántica y se extiende con la narrativa realista". Véanse también, entre otros, Cano Aguilar (2017), Carpi (2019), Martí Sánchez (2020), Méndez Orense (2021), así como las contribuciones reunidas en López Serena, Del Rey Quesada y Carmona Yanes (eds.) (2020). 
cambios lingüísticos en la historia de una lengua si no es vinculados a su presencia en algunas tradiciones que, condicionadas por las finalidades pragmáticas de la situación de comunicación, generan un discurso determinado que se repite en constelaciones de entornos semejantes" ${ }^{25}$. También en la última década, Carmona Yanes (2011) y Leal Abad (2020) han comenzado a estudiar la construcción histórica de los anuncios periodísticos, en el marco de dos proyectos de investigación cuyos títulos hacen referencia explícita al modelo de las $\mathrm{TD}^{46}$.

\subsection{Hispanoamérica}

Como se anticipó ya en $\mathbb{S} 1$, las cuatro áreas geográficas hispanoamericanas en las que es posible detectar un mayor interés por la investigación sobre TD son el Caribe, Perú, México y Uruguay. En relación con el Caribe, los trabajos, ya mencionados, de Martha Guzmán enlazan, por un lado, con la reivindicación - enunciada ya anteriormente en $\mathbb{S}$, a propósito del concepto de recontextualización - de tener en cuenta, en la interpretación de cada dato lingüístico individual, la complejidad del contexto histórico que lo envuelve, así como, por otro lado, con la crítica frente a las tradicionales visiones lineales de la evolución lingüística esgrimidas por la corriente de las TD y que llevan a los representantes de este paradigma a poner en entredicho la viabilidad de hacer historia de la lengua a partir, exclusivamente, de corpus informatizados en cuya confección no se haya tenido en cuenta el problema de las TD

\footnotetext{
45 Sobre los inicios del discurso periodístico, véanse asimismo Leal Abad (2011 y 2016) y Fernández Alcaide y Leal Abad (2016).

46 Se trata de los proyectos I $+\mathrm{D}$ “Tradiciones discursivas, tradiciones idiomáticas y unidades de análisis del discurso en la historia del español moderno” (FFI2014-51826-P) y "Tradicionalidad discursiva e idiomática, sintaxis del discurso, traducción y cambio lingüístico en la historia del español moderno: prosa (pre-)periodística/ensayística y literaria” (PGC2018-097823-B-I00). Sobre los principios teóricos y metodológicos en que ambos proyectos se sustentan, véase López Serena (2018).
} 
(véase, a este respecto, Kabatek 2013, 2014) ${ }^{47}$. En relación con esta cuestión, Oesterreicher sostiene que

[n]o son aceptables [...] ciertas opciones en el campo de la llamada teoría de la gramaticalización que prefieren abordar el cambio basándose en información dada y siguiendo modelos unidireccionales del cambio sin anclaje en una documentación textual representativa de un vasto dominio discursivo (cfr. Oesterreicher 2006: 146-153 [...]). Estas orientaciones no analizan previamente lo que fundamenta la investigación lingüística seria, es decir la documentación discursiva con sus riquezas variacionales y pragmáticas (cfr. Oesterreicher 2002 y 2004) (Oesterreicher 2008: 240; cursiva original).

En línea con esta idea, Longhin (2014: 45) señala que “[a] noção de TD vem conquistando, na última década, um estatuto privilegiado nos estudos da linguagem, particularmente nas pesquisas em linguística histórica, por fornecer subsidios para o enfrentamento de um dos grandes desafíos metodológicos do linguista historicista, que é a representatividade do corpus". También en este sentido, Guzmán (2006: 79) se plantea como objetivo "ilustrar en un ámbito concreto, el de la historia de la lengua española en América, en qué medida el trabajo con el concepto de tradiciones discursivas y las formas de análisis a él asociadas resultan no ya útiles, sino indispensables". Tal y como ella sostiene, el acercamiento a través de las TD "permite situar al texto, en tanto que contexto de los fenómenos que analizamos, dentro de una tradición textual, lo que posibilita apreciar con mayor claridad tanto la repetición de elementos lingüísticos de épocas anteriores como las innovaciones $\mathrm{y}$, por consiguiente, poder calibrar las apariciones y apreciar mejor

\footnotetext{
47 Una muestra de la relevancia de esta cuestión para la lingüística histórica contemporánea ha sido la organización, en febrero de 2021, en la Universidad Católica de Lovaina, de un encuentro científico dirigido por Bert Cornillie, Giulia Mazzola y Miriam Thegel, y titulado "Las Tradiciones Discursivas en tiempos de lingüística cuantitativa: ¿corrección epistemológica o deconstrucción metodológica”. Sobre el fuerte arraigo de esta convicción entre los historiadores del portugués brasileño, véase Simões (2017: 688-689), así como Simões y Kewitz (2006, 2009a, 2009b).
} 
los cambios” (Guzmán 2006: 81) ${ }^{48}$. Por este motivo, en las aproximaciones lingüísticas que, como la suya, adoptan la perspectiva de las TD son claves las siguientes preguntas: “¿Con qué fuentes contamos? ¿Qué características desde el punto de vista de las tradiciones discursivas son apreciables en ellas? ¿Qué relevancia pueden tener dichas características para el análisis lingüístico? Y, por último, ¿qué consecuencias negativas puede tener para dichos estudios el no reconocimiento de las tradiciones discursivas en las fuentes de las que se nutren?” (Guzmán 2006: 79). Para esta autora, advertir tanto "que las fuentes con las que trabajamos, más allá de su carácter material [...], son también, de una manera más o menos marcada, representativas de determinadas tradiciones discursivas” (Guzmán 2006: 79) como la importancia del carácter suprarregional de las TD, en el sentido de que "no tienen por qué, y de hecho no suelen, estar circunscritas a una comunidad lingüística” (Guzmán 2006: 81) resulta crucial, por ejemplo, a la hora de relativizar, tanto temporal como espacialmente, la representatividad lingüística de los documentos americanos como fuentes de datos para el estudio del español, no en América, sino de América, que es uno de sus principales ámbitos de investigación (López Serena 2006b: 53) ${ }^{49}$. Guzmán (2006: 81) destaca también "la susceptibilidad de las tradi-

48 Conviene volver a leer también, en este mismo sentido, las palabras de Garatea (2013a: 5, n. 5) citadas más arriba en $\ 1$, así como el pasaje, de este mismo autor, reproducido páginas atrás en la n. 18. En otro lugar (Garatea 2013b: 43), el mismo investigador pondera "la necesidad de encarar los fenómenos y los textos valorando las condiciones comunicativas, el entorno de producción ${ }^{[\cdots]}$. De esta manera, podrá explicarse por qué tal o cuál (sic) fenómeno aparece en un tipo particular de textos y qué dimensiones contribuyen (o no) con su presencia en ese u otros tipos textuales".

49 También Garatea (2013b: 42) considera que "[v]ale la pena insistir en que la historia del español en América es también la historia del español” y en que “[1]a difusión del español en el continente [americano] produjo innovaciones y cambios en distintos niveles, desde el sistemático y funcional hasta el de las tradiciones discursivas, [pero] sin llegar a producir por ello una fractura entre América y España”; por eso destaca cómo "la continuidad de patrones estructurales y léxicos enlaza, por ejemplo, al escribano Napanpoma [...] y al cronista Guamán Poma de Ayala [...], ambos seguramente bilingües [quechua español], con el obispo de Huesca, Vidal de Canellas, primer compilador del fuero de Aragón, Vidal mayor, entre 1250 y 1252, a pesar de las diferencias que, al mismo tiempo, se advierten en los textos y de los siglos que median entre cada uno de los 
ciones discursivas a cambios”, que “pueden entenderse tanto en la expansión, pérdida de importancia, aparición o desaparición de determinadas tradiciones discursivas; (sic) como en las adaptaciones o evoluciones en el interior de una misma tradición discursiva" ${ }^{50}$. En especial, esta autora (2006: 83) llama la atención sobre el problema de representatividad temporal de estos textos porque "no sólo están relacionados con tradiciones muy anteriores al momento en el que fueron concebidos, sino que además se caracterizan por un alto grado de conservadurismo e inflexibilidad textual, por lo que su producción viene muchas veces formalmente pautada de antemano por individuos o instituciones" ${ }^{51}$ y espacialmente por el hecho de que las TD no están circunscritas a una determinada región.

A los trabajos dedicados por Martha Guzmán a las TD del Caribe, cabe sumar los estudios de Carlos Garatea (2004, 2006, 2012, 2013a, 2013b, 2016) sobre documentación peruana, las publicaciones de los mexicanos Alfonso Gallegos Shibya (2003, 2011,

autores” (Garatea 2013b: 44). Sobre la cuestión de la representatividad, véanse también Kabatek (2013) y Pons Rodríguez (2006b: 1568).

50 Este tipo de investigación cobra especial relevancia en Brasil (véase a este respecto $\mathbb{\$}$ 3.3.).

51 A la permeabilidad o conservadurismo de las diferentes TD hace alusión también Pons Rodríguez (2006b: 1564-1565), cuando se refiere al hecho de que, en el siglo XV, se producen tanto cambios por imitación latina como cambios que "se implantan y difunden 'de abajo hacia arriba', [que] recorren el camino de la oralidad a los textos, y en ellos, penetran según la permeabilidad y el conservadurismo de cada tradición discursiva". Con respecto a los primeros, la adopción o no de unidades y estructuras latinizantes también depende, en opinión de esta autora, entre otras cosas, de las TD: "la formación, los intereses y el momento en que escribe cada autor, así como la tradición discursiva de su texto permiten predecir hasta cierto punto la entrega a la latinización o el grado de reticencia” (Pons Rodríguez 2006b: 1567); de ahí que, para ella, por lo que concierne al "desvío de los cauces lingüísticos ya dados” que, según Ridruejo (1990: 206), caracterizaban la lengua cuatrocentista, se deba constatar que "su introducción se hace desde arriba y es brusca, su plasmación está DISCURSIVAMENTE CONDICIONADA, y su difusión, cronológicamente acotada" (Pons Rodríguez 2006b: 1567; cursiva original, la versalita es mía). Concretamente, su posición es que, en el siglo XV, por lo que respecta a las tendencias latinizantes, "estamos ante cambios que se dan en las tradiciones concepcionalmente más propias de la distancia comunicativa”, por lo que, a su modo de ver, “[a]tendiendo a las tradiciones discursivas que los reciben, tendríamos en el siglo XV una diferencia entre lo hablado y lo escrito a un nivel que no se había dado antes en castellano" (Pons Rodríguez 2006b: 1571). 
2018, 2020), María Eugenia Vázquez Laslop (2014a, 2014b, 2015, 2018, 2019a, 2019b) y Concepción Company $(2008,2016)$, así como las contribuciones incluidas en Bertolotti y Coll (coords.) (2020) sobre el español del Uruguay en la prensa del s. XIX.

Por lo que concierne al Perú, a lo largo de sucesivos trabajos, Carlos Garatea se ha propuesto llamar la atención sobre la complejidad inherente a la situación de contacto entre quechua y español a la que dio lugar la conquista, en el sentido de que este contacto no se restringe al nivel de los dos sistemas lingüísticos afectados, sino que se extiende a la exposición, de los habitantes autóctonos, “a tradiciones, concepciones y modalidades lingüísticas y culturales ajenas al espacio andino” (Garatea 2013a: 5). En la asunción de esta visión, Garatea — para quien "[l]a historia del español americano es la historia de comunidades hablantes, de tradiciones discursivas y de innumerables situaciones de contacto de lenguas" (Garatea 2016: 51) — da continuidad al pensamiento de Rivarola (2007: 168) (véase Garatea 2013a: 4, n. 3), que ya había puesto de relieve cómo el "conjunto de tradiciones de habla que una comunidad posee en un equilibrio inestable [...] no se circunscribe al puro inventario de formas lingüísticas” y recuerda que:

Como en toda situación comunicativa, en el contacto entra en juego la competencia de los hablantes y, en ella, interviene un conocimiento que, por una parte, incumbe a las unidades gramaticales y, por otra, recae en saber cómo hacer que la expresión se configure de acuerdo con tradiciones aseguradas y diferenciadas en la comunidad, lo que indudablemente reditúa en el desempeño pragmático (Garatea 2013a: 8).

De ahí que afirme no encontrar motivo para mantener la atención hacia las TD "fuera de las reflexiones sobre el contacto de lenguas" y se pregunte: “ $¿$ Acaso el contacto no compromete el conocimiento lingüístico en lo gramatical y en lo discursivo?” (Garatea 2013a: 8); y de ahí también su interés por examinar cómo "los receptores indígenas $[\ldots]$ dieron otro entorno pragmático a las tradiciones europeas trasladadas al Nuevo Mundo” (Garatea 2013b: 41). 
Un ejemplo concreto de cómo los habitantes autóctonos del Perú se valieron de las TD de los conquistadores en sus propios escritos se puede ver en el trabajo que Garatea dedica a Guamán Poma de Ayala en 2016, en cuyas páginas se destaca cómo, al dirigirse al rey, este personaje histórico encuentra el medio apropiado "en una lengua adquirida al servicio de curas y notarios y, claro, en las tradiciones discursivas que considera pertinentes para elaborar su obra" (Garatea 2016: 55), inspirándose, en gran medida, en "las instrucciones retóricas [...] que contiene el Proemio del Tercero catecismo y exposición de la doctrina cristiana por sermones para que los curas y otros ministros prediquen y enseñen a los indios a las demás personas, conforme a lo que se proveyó en el santo concilio de la ciudad de Lima de 1583" (Garatea 2016: 60) ${ }^{52}$.

En cuanto a México, Gallegos Shibya (2018: 14) se inspira "en el postulado de que «hablar no es sólo decir algo a alguien sobre las cosas de acuerdo con las reglas de un[a] lengua (esto es, su sistema y su norma), sino que suele ser, además, decir algo según una determinada tradición textual de hacerlo»" (Kabatek 2005a: 156) ${ }^{53}$. Para este autor ${ }^{54}$, en sintonía con lo que se señaló ya a propósito de Jacob

\footnotetext{
52 Sobre este texto, véase también Ezcurra (2016).

53 Véase asimismo Kabatek (2008: 9, citado por Gallegos Shibya 2018: 16): “la historia de la lengua no presenta solo variación a nivel de dialectos, sociolectos o estilos[,] sino que la lengua varía también de acuerdo con las tradiciones de los textos, es decir, que estos no sólo añaden sus elementos formales, sus características de género o las marcas de un tipo determinado de estructuración a los productos de sistemas ya dados[,] sino que condicionan o pueden condicionar, a su vez, la selección de elementos procedentes de diferentes sistemas (o de un sistema de sistemas)" (cursiva original). La misma cita de Kabatek se puede encontrar, traducida al portugués brasileño, en Castilho (2015: 285).

54 Gallegos dedicó su tesis doctoral (Gallegos Shibya 2011) a las relaciones entre morfopragmática y TD en el desarrollo de la nominalización en el registro técnico en español. En un artículo de 2020, remite también a la definición de Oesterreicher (1997), de acuerdo con la cual "las tradiciones discursivas representan modelos o esquemas históricocontingentes que guían la producción y recepción de cualquier texto o discurso y que, si bien rebasan el marco de las lenguas individuales, seleccionan en estas, al menos parcialmente, el uso de una variedad lingüística o modelos de habla determinados" (Gallegos Shibya 2020: 570). Ecos de esta definición de Oesterreicher parecen resonar también en las siguientes palabras de Garatea (2013b: 47): “todo hablante está siempre integrado en redes sociales o de interlocución en las que desarrolla, usa y perfecciona su competencia lingüística y aprende a actuar verbalmente de acuerdo a los modos esperables en cada uno
} 
y Kabatek (2001), la importancia del modelo de las TD "reside en que constituye un eslabón entre los aspectos 'internos' y 'externos' de la lengua" 55 , de manera que se hace "posible relacionar aspectos anteriormente considerados 'externos' —como las circunstancias performativas de los textos o su contenido- con otros 'internos' - como los elementos propiamente gramaticales-, lo cual ha permitido apreciar el complejo problema del cambio lingüístico desde una nueva perspectiva” y focalizar, por ejemplo, "esta interacción a partir del concepto de elaboración lingüística” (Gallegos Shibya 2018: 14; cursiva original).

Por cuanto respecta a Vázquez Laslop —que, en uno de sus trabajos más recientes (2019a), aplica al análisis discursivo-tradicional que emprende el modelo de junción de Raible (1992) que sirvió de

de los contextos que constituyen su mundo de interacción social”. En ocasiones, el autor mexicano se duele de que, si bien desde el punto de vista de las TD se ha atendido al hecho de que "la difusión y consolidación de (al menos parte de las) innovaciones lingüísticas pueden ser entendidas como respuesta a necesidades expresivas y funcionales específicas que resultan de la adopción de nuevos contenidos y formas textuales [...], el fenómeno opuesto no ha recibido la misma atención, a saber, que las tradiciones discursivas también pueden propiciar el mantenimiento de ciertos elementos lingüísticos que en otras variedades lingüísticas ya no son productivas (o no lo son en la misma medida)" (Gallegos Shibya 2018: 14; cursiva original). La verdad es que esta queja no se entiende muy bien, toda vez que el consenso en torno al hecho de "que se debe contar com certo conservadurismo das tradiçōes discursivas, isto é”, con el hecho de que "nelas permanecem elementos constituintes de tradições subjacentes” es general (la cita es de Castilho 2015: 299, quien remite en este punto a Koch 1997: 64). Recuérdese asimismo el texto de la cita de Guzmán (2006: 83) que consideramos pertinente volver a reproducir aquí: los textos que conservamos para el estudio del español en América "no sólo están relacionados con tradiciones muy anteriores al momento en el que fueron concebidos, sino que además se caracterizan por un alto grado de conservadurismo e inflexibilidad textual, por lo que su producción viene muchas veces formalmente pautada de antemano por individuos o instituciones". En el mismo sentido se expresa, en todos sus trabajos sobre TD, Vázquez Laslop, así como Garatea (2012: 94): "Pienso que debe tenerse presente que la llegada del español al continente [americano] estuvo acompañada de la escritura, de textos y de modelos y tradiciones asegurados en siglos de cultura escrita", algo que queda patente, por ejemplo, cuando este autor afirma que los escritos del fiscal eclesiástico de origen inca Agustín Capcha, de los que se ocupa en ese mismo trabajo, "están obviamente hermanados con una prolongada tradición textual que arraigó en América y que liga a la Edad Media con la América Colonial” (Garatea 2012: 98). Véase también, ya por último, más arriba la n. 51.

55 Véase asimismo Company (2008). 
inspiración a Kabatek (2005c)—, sus esfuerzos se han concentrado en rastrear los cambios textuales que acompañaron la transición, en México, desde el derecho indiano a la codificación legislativa, secundadora del código napoleónico, que tuvo lugar en la época de la Independencia, hasta llegar a las actuales leyes especiales, que considera características de una era que los historiadores del Derecho han denominado de decodificación. A tenor de las diferentes calas que ha realizado en elámbito delajurisprudencia mexicana, esta autora-una de las pocas especialistas contemporáneas que suele reproducir, en sus trabajos, la figura que en este artículo lleva el número 4 y que se suele hacer eco de la propuesta, hecha por Oesterreicher (2011b), de atender a la vinculación entre TD y referencia- concluye que "los cambios ideológicos en el ámbito jurídico no dan lugar drásticamente a cambios en las estructuras textuales, sino que cada nuevo paradigma jurídico repite elementos lingüísticos de paradigmas anteriores y los combina con otros innovadores, sin necesariamente dar lugar a tradiciones textuales radicalmente diferentes" (Vázquez Laslop 2014b: 88). Más recientemente (Vázquez Laslop 2019b), esta misma investigadora ha recuperado la idea, expresada por Koch (1998), de que los documentos jurídicos propios de la tradición occidental hunden sus raíces en los moldes grecolatinos de la retórica y la escritura epistolar, tal y como ponen de manifiesto los rasgos discursivo-tradicionales que permiten trazar una línea desde el ars dictaminis medieval a la legislación mexicana contemporánea.

Por lo que respecta a Concepción Company, esta autora, que no podemos considerar representante del paradigma de las TD propiamente dicho, se ha caracterizado por tratar de complementar los avances de la teoría de la gramaticalización con propuestas que atienden a la variación lingüística como las de $\operatorname{Biber}(1986,1995)$ o el modelo de las TD, debido a su convicción de que "el cambio gramatical depende en gran medida y está condicionado por la situación comunicativa, por el género textual y el registro situacional en que se escribe y emplea ese texto, por las tradiciones culturales en que se producen los textos y, desde luego, por la conformación social y actitud lingüística del grupo de usuarios de la lengua" 
(Company 2008: 21). A tenor de esto, plantea que "el género discursivo" - etiqueta que, en su opinión, "se recubre casi totalmente con el término 'registro' empleado por Biber [...] y la tradición sociolingüística, pero [...] que atiende también al concepto más amplio de tradiciones discursivas' empleado por las corrientes” del modelo de las TD, que ella denomina "Nueva Filología” (Company 2008: 37, n. 11) - "puede ser condicionante tanto de la creación e innovaciones sintácticas cuanto de su difusión” (Company 2008: 37; véase también Company 2016).

En cuanto al proyecto de investigación sobre "Lengua y prensa en el Uruguay del siglo XIX” dirigido por Virginia Bertolotti y Magdalena Coll, cuyos primeros resultados se pueden consultar en Bertolotti y Coll (coords.) (2020), su ejecución ha auspiciado trabajos, como el de Hernán Viera (2020), interesado por el trasvase, a los nuevos géneros periodísticos en emergencia a principios del s. XIX en esta zona del Cono Sur, de formas discursivas como las proclamas o los alegatos jurídico-políticos, los bandos públicos o los partes de guerra, con los que tanto los redactores como los lectores de esta primera prensa estaban familiarizados anteriormente. En ese mismo volumen, la propia Bertolotti interpreta la preeminencia de vosotros sobre ustedes en los textos periodísticos de la primera mitad del XIX analizados por ella como un fenómeno discursivo-tradicional, lo que la lleva a concluir que "el concepto de tradiciones discursivas es efectivamente explicativo, ya que permite dar cuenta, en forma sistemática y a través de datos empíricos, de cuestiones a veces tratadas como estilíticas y a veces como formulaicas (como el pretérito perfecto compuesto al comienzo de las cartas) ${ }^{[56]}$, arrastres arcaizantes (como la construcción con dislocación viuda que fui) ${ }^{[57]}$ e innovaciones por especialización (como la resemantización de vosotros) ${ }^{[58]}$ " (Bertolotti y Coll 2020: 14).

\footnotetext{
56 Véase Álvarez (2020).

57 Véase González Zunini (2020).

58 Véase Bertolotti (2020).
} 


\subsection{Brasil}

Los principales estudios sobre TD en Brasil han surgido en el contexto del Projeto para a História do Português Brasileiro (PHPB) (Proyecto para la Historia del Portugués Brasileño), dirigido por Ataliba T. del Castilho desde $1997^{59}$, y que cuenta en la actualidad ya con ocho volúmenes, uno de los cuales (véase Andrade y Gomes coords. 2018), cuyo título es, justamente, Tradições discursivas do Português Brasileiro: constituição e mudança dos gêneros discursivos, está específicamente dedicado a las $\mathrm{TD}^{60}$. Como anuncia el título de este volumen colectivo, la constitución y la transformación de determinados géneros o tipos textuales y, concretamente, de los esquemas que conforman la estructura de diferentes tipos textuales, es, efectivamente, uno de los objetos de estudio predilectos de los lingüistas brasileños que se hacen eco, en sus contribuciones, de la noción de TD, y que aducen, incluso en relación con la relevancia de esta perspectiva "para a constitução dos corpora”, la necesidad de tener "en comta a importancia da história dos géneros textuais e de sua circulação no Brasil ao longo da história do país” (Simões 2017: 684) ${ }^{61}$ :

Os criterios de seleção dos corpora devem ter em conta (i) a historicidade linguística no sentido próprio (historicidade da língua em particular), (ii) a historicidade da tradição (repetição) dos géneros (carta, anuncios, atas paroquiais, memorias históricas, entremeses e peças teatrais etc) e (iii) a historicidade genérica dos elementos discursivos constantes desses textos (Simões 2017: 691; cursiva original).

\footnotetext{
59 Sobre la trayectoria y los equipos de investigación que conforman este proyecto —al que hace referencia Kabatek (2005a; 2008)—, se puede ver, por ejemplo, Simões (2017: 683-684).

60 Otros títulos interesantes en este sentido son los que llevan los números monográficos de la revista LaborHistórico dedicados a las Interseções entre a bistoricidade da língua e a historicidade do texto sob a ótica das Tradiçōes Discursivas y Tradições Discursivas: faces e interfaces da historicidade da lingua e do texto, coordinados en 2018 por Cleber Alves de Ataíde y Valéria Severina Gomes.

${ }^{61}$ Sobre la importancia de las TD para la constitución de corpus, véase también Simões y Kewitz (2006, 2009a, 2009b).
} 
Ello está en consonancia con la convicción de que, "[n]o estudo da história da língua, mostra-se proveitoso considerar a história dos textos, isto é, as relações entre o uso de determinados fenómenos linguísticos e a existencia de TD" (Castilho 2011: 278). Entre los trabajos que engloba ese volumen de la História do Português Brasileiro, podemos mencionar, dentro de esta línea de investigación, las contribuciones (i) de Gomes y Zavam (2018) sobre "o percurso sócio-histórico do editorial como prática discursiva do jornalismo impresso, a fin de examinar a manutenção e/ou inovação de aspectos ligados tanto à localização no corpo jornal quanto à dimensão linguístico-discursiva" (Andrade y Gomes 2018: 17); (ii) de Ataíde y Travassos (2018) sobre la noticia periodística, capítulo que "objetiva investigar que mudanças podem ser apontadas na estrutura da noticia jornalística da mídia impressa" (Andrade y Gomes 2018: 18), o (iii) la contribución de Matias (2018), quien busca "reconstruir a história do gênero carta de leitor, por meio de uma análise discursivo-textual do gênero a fim levantar características internas e identificar o que mudou ou permaneceu no uso/ circulação e constituição do gênero, desde o seu surgimento até o século XX" (Andrade y Gomes 2018: 19) ${ }^{62}$.

Pese a que para introducirse en la investigación sobre TD en Brasil el volumen coordinado por Andrade y Gomes (coords.) (2018) pueda antojarse, por su título, la mejor vía de acceso, es importante indicar que estas autoras basan sus propios acercamientos en la tesis doctoral inédita de José da Silva Simões $(2007)^{63}$, algunos de cuyos contenidos han visto la luz en artículos publicados por este autor, bien en solitario (véase Simões 2012), bien conjuntamente con Verena Kewitz (véase Simões y Kewitz 2006, 2009a, 2009b).

Otra autora de referencia en el panorama brasileño sobre TD, cuyos trabajos se han mencionado ya en diversas ocasiones a lo

62 Sobre la conformación histórica de las cartas de los lectores, véanse también Castilho (2011) y Carmona Yanes (2019).

${ }_{63}$ Trabajo al que remite Andrade (2008) en varias ocasiones. Véase ahora también Simões (2020). 
largo de estas páginas, es Alessandra Castilho da Costa. Germanista de formación, como Simões, esta lingüista, que por su dominio del alemán ha tenido acceso directo a las fuentes teóricas de este modelo de investigación, ha aplicado la visión de las TD a estudios sobre la evolución de TD como las actas parroquiales de bautismo, casamiento y defunción (Simões y Castilho 2009), los anuncios publicitarios (Castilho 2010), las cartas de lectores (Castilho 2011), los testamentos (Castilho 2015) o las traducciones de la Biblia al portugués (Castilho 2020) ${ }^{64}$. Sus aproximaciones se pueden considerar emblemáticas de la convicción que impera en los estudios de historia del portugués brasileño en torno al hecho de que "a autonomía do nível histórico das tradições discursivas e a relação entre tradição discursiva e mudança lingüística, tornam necessária a pesquisa da evolução dos géneros textuais de um ponto de vista diacrónico" (Castilho 2011: 278) y son un buen ejemplo de cómo se investigan, en su país, "as relações de evocação ${ }^{65}$ que se establecen", por ejemplo, "entre diferentes textos reguladores", como los "manuais de bem morrer" que ella analiza, "e os testamentos" cuya producción se veía facilitada por los modelos que proveían dichos manuales de bien morir (Castilho 2015: 299). Precisamente en su estudio de las relaciones de filiación intertextual de un conjunto de testamentos redactados en el estado brasileño de Rio Grande do Norte, Castilho pone en práctica el análisis de los mecanismos de junción (véase Raible 1992) —que ya habíamos mencionado en $\ 3.2$ a propósito de Vázquez Laslop (2019a) - en cuyo examen — como también habíamos señalado ya - se centra la monografía de Kabatek (2005c):

$\mathrm{Na}$ análise apresentada, a hipótese de que diferentes filiações históricas dão preferencia a diferentes técnicas de junção pôde ser comprovada por meio da idetificação de duas diferentes filiações históricas em nossos dados: o modelo textual proposto pelo Breve Aparelho e aquele proposto pelo Tratado regular e prático. Com a

${ }^{64}$ De otro género distinto, la historia de las recetas culinarias como TD, se ocupa Longhin (2014).

${ }_{65}$ Recuérdese la definición de TD de Kabatek (2005a) reproducida más arriba en $\$ 1$. 
identificação dos juntores típicos dessas duas tradições discursivas, pudemos reconhecer as famílias de textos internas ao nosso agrupamento de testamentos. Nesse sentido, o presente estudo corrobora a tese de Kabatek (2006) de que as técnicas de junção funcionam como síntomas de tradições discursivas (Castilho 2015: 314) ${ }^{66}$.

\section{Conclusiones}

En su recepción fuera de las fronteras de la Romanística alemana, el paradigma de las TD se ha aplicado, fundamentalmente, al análisis histórico del español y el portugués brasileño ${ }^{67}$. Las tradiciones de estudio diacrónico de ambas lenguas comparten un mismo conjunto de referencias bibliográficas de partida y una comunión de intereses de investigación, entre los que destaca la alusión continua a la noción de recontextualización acuñada por Oesterreicher $(2001,2003)$ y la invocación sistemática a la definición de TD formulada por Kabatek (2005a y 2006) y, en menor medida, a las de Jacob/Kabatek (2001) y Oesterreicher (1997). En general, podríamos considerar que los historiadores de la lengua española y los historiadores del portugués brasileño coinciden, en primer lugar, en dar preferencia, en sus aproximaciones, al concepto de TD por encima del de género, si bien en ambas latitudes es frecuente el empleo intercambiable de los sustantivos género y tradición seguidos del adjetivo discursivo/a. Hay, en segundo lugar, también una voluntad decidida, a ambos lados del Atlántico, por prestar atención, en todos los casos, a la complejidad del contexto histórico, social y cultural en el que se originan los textos que sirven, bien como fuentes de datos para el estudio, bien como objetos de estudio en sí mismos, para lo que se suele hacer referencia al concepto de recontextualización de Oesterreicher $(2001,2003)$. Con todo, también es posible percibir algunas

\footnotetext{
66 Este mismo tipo de análisis es aplicado por Longhin-Thomazi y Rodrigues (2013) a las "cartas de aldeamento".

${ }_{67}$ Para el italiano, lengua en la que Koch (1987) centró precisamente su tesis de habilitación, véanse De Roberto (2013), Giovanardi/De Roberto (2015), Burgassi/Guadagnini (2017) y Greco (2019).
} 
diferencias relativas a las tendencias que predominan con respecto a una y otra lengua, que se destacan por separado a continuación.

Por un lado, en los estudios sobre el español son más frecuentes que en Brasil las formulaciones expresas de rechazo tanto hacia las categorizaciones apriorísticas y de vocación universalista propias de la tipología textual, como a la conversión de la lingüística histórica en una lingüística de corpus que no tenga en cuenta los factores discursivo-tradicionales que condicionan la interpretación de cualquier dato lingüístico, así como las vindicaciones de la necesidad de superar la visión lineal de la evolución de las lenguas que, de acuerdo con Kabatek (2008: 8), "parte del supuesto de la existencia de una - y una sola - gramática representativa de cada lengua y cada época".

Por otro lado, mientras que en la lingüística histórica española es posible identificar (i) análisis de las diferencias lingüísticas que presentan pares o grupos de textos que mantienen entre sí una relación intertextual fundamentada en la identidad de contenido, pero con modificaciones relativas a la forma, debido a que el modelo y sus refacciones posteriores no comparten una misma orientación discursivo-tradicional; (ii) trabajos que examinan tanto procesos de elaboración lingüística como, sobre todo, de gramaticalización o evolución de construcciones lingüísticas emanadas de tales procesos, que, por oposición con respecto a las innovaciones debidas a la expresividad, consideradas cambios "desde abajo", se interpretan como cambios "desde arriba" o como cambios promovidos desde TD de la distancia; y (iii), de momento, solo esporádicamente, exploraciones de los cambios experimentados, a lo largo de la historia, por los tipos textuales característicos de unas y otras épocas, en Brasil, este tercer tipo de contribuciones es, junto con el rastreo de la posible presencia de rasgos de oralidad en textos antiguos, el más frecuente. Recuérdese, a este respecto, cómo, de acuerdo con Castilho (2011: 278), “a pesquisa da evolução dos géneros textuais de um ponto de vista diacrónico" es, no solo interesante, sino incluso "necessária". A la inversa, tanto en Brasil como, de momento, también en Hispanoamérica, escasean los dos 
tipos de acercamiento más frecuentes en España: los que analizan convergencias y divergencias entre modelos textuales y refacciones basadas en tales modelos (véase ahora, por ejemplo, López Izquierdo 2020) y los que atienden al desarrollo de unidades y estructuras vinculadas con los procesos de elaboración lingüística. Notables excepciones en este sentido son los trabajos de Castilho sobre las relaciones de filiación intertextual entre una selección de testamentos que esta autora estudia en relación con los manuales de bien morir que les sirven de fuente para algunas partes de su estructura y contenido (véase, de nuevo, a este respecto, $\int 3$ ) y los que Vázquez Laslop dedica al estudio de la configuración histórica del discurso jurídico en México. Con todo, pese a las lagunas que aún será preciso ir rellenando, parece necesario comenzar a matizar el posicionamiento de Garatea (2016: 52) cuando denuncia que "en América, y en concreto, en la historia del español americano” "el interés por la oralidad, la escritura y las tradiciones discursivas" "no provocan el entusiasmo que despiertan en otros lugares"68.

Desafortunadamente, los contactos entre historiadores de la lengua española e historiadores del portugués brasileño son muy esporádicos. Sin embargo, el estrecho vínculo científico que Johannes Kabatek mantiene con los investigadores tanto hispanófonos como lusófonos que han adoptado, en sus trabajos, los principios heurísticos de esta corriente de estudios y el hecho de que todos ellos tomen como referencia un mismo conjunto de publicaciones permite detectar a uno y otro lado del Atlántico un cierto aire de familia. Sin duda, un mejor conocimiento mutuo del tipo de pesquisas que se están haciendo en una y otra tradición podría beneficiar a todas las partes implicadas. En este sentido, creo que el panorama de la lingüística histórica brasileña podría salir fortalecido si prestara una mayor atención a los procesos de elaboración extensiva e intensiva experimentados por el portugués en el conti-

\footnotetext{
68 A la bibliografía sobre español de América y TD que, sin ánimo de exhaustividad, se ha ido citando ya en las páginas precedentes, cabría añadir muchos otros trabajos firmados por discípulos directos de Wulf Oesterreicher, como Stoll (1994, 1996, 1997, 1998, 2005, 2010), Schmidt-Riese (1997) o Ezcurra (2012, 2016).
} 
nente americano y si se aventurara a examinar pares o grupos de textos con una cierta filiación intertextual, en busca de diferencias lingüísticas correlacionadas con la alteración de las características discursivo-tradicionales de los textos considerados, como ha hecho ya, por ejemplo, Castilho (2015). Al mismo tiempo, sorprende que la historia del español haya dedicado aún tan pocos esfuerzos a describir la evolución diacrónica de los diferentes géneros o tipos textuales, tarea para la que podría encontrar excelentes fuentes de inspiración en la bibliografía brasileña, que, como hemos visto, considera imprescindible esta línea de investigación.

\section{REFERENCIAS BIBLIOGRÁFICAS}

Álvarez, Soledad

2020 "El pretérito perfecto compuesto en el español uruguayo del siglo XIX”. En Bertolotti y Coll (coords.) 2020: 109-142.

Andrade, Maria Lúcia da Cunha Victório de Oliveira

2008 "Cartas do leitor: A interatividade na correspondencia publicada em jornais”. Revista da Anpoll. 1, 25. https://doi. org/10.18309/anp.v1i25.58

Andrade, Maria Lúcia C.V.O. y Valéria Gomes (coords.)

2018 Tradições discursivas do Português Brasileiro: constituição e mudança dos gêneros discursivos. São Paulo: Editora Contexto / Facepe / LeDoc.

Ataíde, Cleber y Tarcísia Travassos

2018 "A noticia de jornal entre conservação e inovação: tradições discursivas e história da língua”. En Andrade y Gomes (coords.) 2018: 82-111.

AuERBACH, Erich

[1950] 1966 Mimesis. Ciudad de México: Fondo de Cultura Económica.

Bertolotti, Virginia

2020 "Los tratamientos plurales en la prensa emergente en el Uruguay del siglo XIX”. En Bertolotti y Coll (coords.) 2020: 43-67. 
Bertolotti, Virginia y Magdalena Coll

2020 “Presentación”. En Virginia Bertolotti y Magdalena Coll (coords.) 2020: 9-15.

Bertolotti, Virginia y Magdalena Coll (coords.)

2020 Las formas del decir. La prensa en Uruguay en el siglo XIX. Montevideo: Doble Clic. <https://fic.edu.uy/noticia/ las-formas-de-decir-la-prensa-en-uruguay-en-el-siglo-xixnuevo-libro-de-la-fhce-y-la-fic >.

Bertolotti, Virginia y Concepción Company Company

2018 "El corpus para América: CORDIAM". En Historia del léxico español y Humanidades digitales. Eds., Dolores Corbella, Alejandro Fajardo y Jutta Langenbacher-Liebgott. Berlín: Peter Lang, 75-105.

BiBer, Douglas

1986 "Spoken and written textual dimensions in English: Resolving the contradictory findings". Language. 62, 2, 384-414. https:// doi.org/10.2307/414678

Biber, Douglas

1995 Dimensions of register variation. Cambridge: Cambridge University Press.

Borreguero Zuloaga, Margarita

2006 "Las tipologías textuales en la lingüística contemporánea: qué se ha hecho y qué queda por hacer”. En Fernández Alcaide y López Serena (eds.) 2006: 55-65.

Burgassi, Cosimo y Elisa Guadagnini

2017 La tradizione delle parole. Sondaggi di lessicologia storica. Estrasburgo: Éditions de Linguistique et de Philologie.

Bustos Gisbert, Eugenio y Rafael Cano Aguilar (eds.)

2020 Noventa años de Orígenes del español. Valencia: Tirant lo Blanch.

Bustos Tovar, José Jesús de

2006

"Los textos literarios en la historia lingüística de Menéndez Pidal”. En Actas del VI Congreso Internacional de Historia de la Lengua Española (Madrid, 29 de septiembre-3 de octubre 2003). Eds., José Jesús de Bustos Tovar y José Luis Girón 
Alconchel. Madrid: Universidad Complutense de Madrid/ Arco Libros/Asociación de Historia de la Lengua Española. Vol. II, 1855-1864.

Bustos Tovar, José Jesús de y Rafael Cano Aguilar (eds.)

2009 La obra de Lapesa desde la Filología actual. Madrid: Sociedad Estatal de Conmemoraciones Culturales.

Cano Aguilar, Rafael

2003 "Sintaxis histórica, discurso oral y discurso escrito". En Textualización y oralidad. Coord., José Jesús de Bustos Tovar. Madrid: Visor, 27-50.

Cano Aguilar, Rafael

2017 "A la búsqueda de los textos olvidados. Los orígenes de la modernidad discursiva en la historia del español”. Romanistisches Jabrbuch. 68, 279-301.

Cano Aguilar, Rafael

En prensa (a) "Discourse Traditions and the historical construction of discourse". En Manual of Discourse Traditions in Romance. Eds., Esme Winter-Froemel y Álvaro S. Octavio de Toledo y Huerta. Berlín: De Gruyter.

Cano Aguilar, Rafael

En prensa (b) "Cambios en la arquitectura discursiva". En Manual de lingüística bistórica del español. Eds., Gloria Clavería Nadal, Steven Dworkin y Álvaro S. Octavio de Toledo y Huerta. Londres: Routledge.

CARmona Yanes, Elena

2011 "Configuración de tipos textuales en los inicios de la prensa española: los anuncios”. En Id est, loquendi peritia. Aportaciones a la lingüistica diacrónica de los Jóvenes Investigadores de Historiografía e Historia de la Lengua Española. Coords., Elena Carmona y Santiago del Rey. Sevilla: Servicio de Publicaciones de la Universidad de Sevilla, 159-169.

Carmona Yanes, Elena

2019 Tres siglos de cartas de lectores en la prensa española. Estudio discursivo histórico. Berlín: Peter Lang. 
CARPI, Elena

2019 "Tradiciones discursivas en una polémica dieciochesca entre aristotélicos y novatores”. VenPalabras. 2, 281,292. DOI: 10.30687/978-88-6969-380-9/009

Castillo da Costa, Alessandra

2010 "Anuncios publicitários do século XIX na imprensa paulista". En Comunicação, cognição, media. Eds., Augusto Soares da Silva, José Cãndido Martins, Luisa Magalhães y Miguel Gonçalves. Braga: Publicações da Facultade de Filosofia Universidade Catolica Portuguesa, 191-206.

Castillo da Costa, Alessandra

2011 "Cartas de leitor em jornais paulistas dos séculos XIX e XX: evolução de uma tradição discursiva". En Linguística do portugués. Eds., Matthias Arden, Christina Märzhäuser y Benjamin Meisnitzer. Múnich: Martin Meidenbauer Verlagsbuchhandlung, 359-376.

Castilho da Costa, Alessandra

2015 "«Por quanto esta he mina ultima vontade do modo que tenho dito». Tradições discursivas textuais e lingüísticas em testamentos norte-rio-grandenses dos séculos XVIII a XX”. En Winter-Froemel y otros (eds.) 2015: 285-316.

Castilho da Costa, Alessandra

2020 "Apresentativos entre indicatividade e predicatividade. En Ilari y Basso (coords.) 2020: 370-413.

Castillo Lluch, Mónica

2001 "El desarrollo de las expresiones de excepción en español antiguo: el caso de la tradición jurídica”. En Jacob y Kabatek (eds.) 2001: 29-44. https://doi.org/10.31819/9783865278432003

Castillo Lluch, Mónica y Lola Pons Rodríguez (eds.)

2011 Asi se van las lenguas variando. Nuevas tendencias en la investigación del cambio lingüistico en español. Berna: Peter Lang.

Company Company, Concepción

2008 "Gramaticalización, género discursivo y otras variables en la difusión del cambio sintáctico”. En Kabatek (ed.) 2008: 17-51. 
Company Company, Concepción

2016 "Sintaxis histórica y tradiciones discursivas. El género textual como macrolocus del cambio sintáctico". En El español a través del tiempo. Estudios ofrecidos a Rafael Cano Aguilar. Dirs., Araceli López Serena, Antonio Narbona Jiménez y Santiago del Rey Quesada. Sevilla: Editorial Universidad de Sevilla. Vol. 1, 385-413.

Coseriu, Eugenio

[1957] 1988 Sincronía, diacronía e historia. El problema del cambio lingüistico. Madrid: Gredos.

Coseriu, Eugenio

1983 "Linguistic Change Does not Exist". Linguistica nuova ed antica. Año I. Galatina, 51-63.

COSERIU, Eugenio

2019 Competencia lingüistica y criterios de corrección. Ed., Alfredo Matus Olivier y José Luis Samaniego Aldazábal. Sevilla: Editorial Universidad de Sevilla.

Del Rey Quesada, Santiago

2015 "El «latín cotidiano» como referencia estilística en la conformación del discurso dialógico castellano (s. XVI)". En Winter-Froemel y otros (eds.) 2015: 209-230.

Del Rey Quesada, Santiago

2016 "Ocho tipos de lengua, cara a cara: las traducciones de la epístola ovidiana de Dido a Eneas en la Edad Media y el Siglo de Oro”. En Título del libro. Dirs., Araceli López Serena y otros. Vol. I, 415-439.

Del Rey Quesada, Santiago

2019 "Variantes de la oralidad elaborada en la segunda mitad del siglo XIX: dos traducciones coetáneas de Los cantivos de Plauto". Oralia. 22, 283-326.

Del Rey Quesada, Santiago

2021 Grupos léxicos paratácticos en la Edad Media romance: caracterización lingüistica, influencia latinizante y tradicionalidad discursiva. Berna [etc.]: Peter Lang. 
De Roberto, Elisa

2013 "Introduzione: le formule nella percezione del parlante e nella ricerca linguistica”. En Il linguaggio formulare in italiano tra sintassi, testualità e discorso. Atti delle Giornate Internazionali di Studio Università Roma Tre, 19-20 gennaio 2012. Eds., Claudio Giovanardi/Elisa De Roberto. Nápoles: Loffredo, 13-32.

EBERENZ, Rolf

1994 "Enlaces conjuntivos y adjuntos de sentido aditivo en el español preclásico: otrosí, eso mismo, asimismo, además, también, aún, etc.”. Iberoromania. 39, 1-20.

Estellés Arguedas, María

2011 Gramaticalización y paradigmas. Un estudio a partir de los denominados marcadores de digresión en español. Berna: Peter Lang.

EzCURRA Rivero, Álvaro

2012 "Ritmos discursivos y licencias semántico-referenciales: aproximación al sermonario de Fernando de Avendaño (1649)”. Allpanchis. Año XLIII, n. 79, 1. ${ }^{\text {er }}$ semestre, 147-172.

EzCURRA Rivero, Álvaro

2016 "Del Tercero catecismo por sermones (1585) a los Sermones de los misterios de nuestra santa fe católica (1649): continuidades temáticas y sintáctico-discursivas”. Cuadernos de la ALFAL. 8, 88-98.

Fernández Alcaide, Marta

2008 "Historia de «con tanto" como posible marcador del discurso". Romanistisches Jabrbuch. 59, 361-375. https://doi.org/ 10.1515/9783110209044.2.3.361

Fernández Alcaide, Marta y Elena Leal Abad

2016 "La expresión de la ponderación en documentos no literarios: tratamiento discursivo de la enfermedad en las relaciones de sucesos del siglo XVII catalogadas en el Fondo antiguo de la Universidad de Sevilla”. En En la estela del Quijote: cambio lingüistico, normas y tradiciones discursivas en el siglo XVII. Coords., Marta Fernández Alcaide, Elena Leal Abad y Álvaro Octavio de Toledo. Fráncfort del Meno: Peter Lang, 351-372. 
Fernández Alcaide, Marta y Araceli López Serena (eds.)

2006 Cuatrocientos años de la lengua del Quijote. Estudios de historiografía e historia de la lengua española. Sevilla: Servicio de Publicaciones de la Universidad de Sevilla.

FERnÁndez Pérez, Milagros

1993 “Sociolingüística y Lingüística”. Lingüística Española Actual. XV. 2, 149-248.

Fernández Pérez, Milagros

1999 Introducción a la linguística: dimensiones del lenguaje y vías de estudio. Barcelona: Ariel.

Gallegos Shibya, Alfonso

2003 Nominalización y registro técnico. Algunas relaciones entre morfopragmática, tradiciones discursivas y desarrollo de la lengua en español. Universidad de Friburgo. Tesis doctoral. $<$ https://freidok.uni-freiburg.de/data/2622>.

Gallegos Shibya, Alfonso

2011 “Tradiciones discursivas y variación lingüística: dos fenómenos de cambio lingüístico complementarios”. En Castillo y Pons Rodríguez (eds.) 2011: 171-195.

Gallegos Shibya, Alfonso

2018 "La relación entre tradiciones discursivas y la dinámica de variedades de lengua”. LaborHistórico. 4, 1, 13-30. https:/doi. org/10.24206/lh.v4i1.17487

Gallegos Shibya, Alfonso

2020 "La compleja relación entre tradiciones discursivas y estilo", Revista de Abralin. 19, 3, 568-581.

Garachana Camarero, Mar

2014 "Gramática e historia textual en la evolución de los marcadores discursivos. El caso de «no obstante»". Rilce. 30, 3, 959-984.

Garatea Grau, Carlos

2001 "Variedad de tradiciones discursivas en Orígenes del español de Menéndez Pidal”. En Jacob y Kabatek (eds.) 2001: 249-270. https://doi.org/10.31819/9783865278432-013 
Garatea Grau, Carlos

2004 "Español de América, español del Perú. Sobre normas y tradiciones discursivas”. Lexis. XXVIII (Homenaje a José Luis Rivarola). 397-428.

Garatea Grau, Carlos

2005 El problema del cambio lingüistico en Ramón Menéndez Pidal. El individuo, las tradiciones y la bistoria. Tubinga: Narr.

Garatea Grau, Carlos

2006 “Textos bilingües y variedades del español en América”. Romanistisches Jabrbuch. 57, 313-326.

Garatea Grau, Carlos

2012 "Los textos del contacto y el discurso jurídico en los Andes (siglos XVI y XVII)”. Allpanchis. XLIII. 79, 91-111.

Garatea Grau, Carlos

2013a “El español colonial en dos textos andinos”. Orillas. 2, 2-22.

Garatea Grau, Carlos

2013b "El otro en el contacto: Sobre alteridad e historia del español de América”. Signo y Seña. 23, 39-62.

Garatea Grau, Carlos

2016 “¿Diálogo o mimesis? A propósito de textos coloniales y Guamán Poma de Ayala”. Cuadernos de la ALFAL. 8, 51-64.

Garrido Martín, Blanca

2015 "La historia de vale decir como un marcador discursivo de reformulación”. En Cabiers d'Études Hispaniques Médiévales. 38, 187-206. https://doi.org/10.3917/cehm.038.0187

Giovanardi, Claudio y Elisa De Roberto

2015 "Componente formulare e strategie traduttive in alcuni volgarizzamenti toscani dal francese". En Le Choix du vulgaire. Espagne, France, Italie (XIIIe-XVIe siècle). Eds., Nella Bianchi Bensimon, Bernard Darbord y Marie-Christine Gomez-Géraud. París: Garnier, 103-131.

Girón Alconchel, José Luis

2008 "Tradiciones discursivas y gramaticalización del discurso referido en el Rimado de Palacio y las Crónicas del Canciller Ayala”. En Kabatek (ed.) 2008: 173-196. 
Gomes, Valéria Severina y Aurea Zavam

2018 "O editorial do jornal: revisitando a trajetória de um gênero". En Andrade y Gomes (coords.) 2018: 44-81.

GonzÁlez Bedoya, Jesús

1988 Tratado bistórico de la retórica filosófica. Madrid: Nájera.

GonZÁLEZ Zunini, Macarena

2020 "Descripción y cronología de las relativas explicativas de atributo antepuesto en documentos de archivo y de prensa del Uruguay en los siglos XVIII y XIX”. En Bertolotti y Coll (coords.) 2020: 143-166.

Greco, Paolo

2019 "On the notion of linguistic influence in syntax. Evidence from medieval Italo-Romance texts". Belgian Journal of Linguistics. 33, 11-42. https://doi.org/10.1075/bjl.00021.gre

GuZmán Riverón, Martha

2006 "Tradiciones discursivas e historia de la lengua española en América”. En Fernández Alcaide y López Serena (eds.) 2006: 79-87.

GuZMÁn Riverón, Martha

2007 Die Texte der Frühen Neuzeit aus der Karibik: Eine Annäherung aus der Perspektive der Diskurstraditionen. Universidad de Múnich. Tesis doctoral.

GuZmán Riverón, Martha

2008 "Tradiciones discursivas en textos coloniales del Caribe: características, origen, evoluciones”. En Actas del VII Congreso Internacional de Historia de la Lengua Española. Eds., José G. Moreno de Alba y Concepción Company. Madrid: Arco/ Libros. Vol. II, 1851-1858.

GuZMÁn Riverón, Martha

2018 "Tradiciones discursivas en textos coloniales de la Audiencia de Quito". En Documentos para la bistoria lingǘstica de la Audiencia de Quito. Ed., Juan Sánchez Méndez. Madrid: CSIC, 59-73 (Anejos de la Revista de Filología Española). 
ILARI, Rodolfo

2020 "Ruídos semânticos na leitura dos textos do PHPB. Relato de uma experiência pessoal”. En Ilari y Basso (coords.) 2020: 48-85.

ILARI, Rodolfo y Renato BASSO (coords.)

2020 História do Português Brasileiro (vol. VIII - História Semântica do Português Brasileiro). São Paulo: Editora Contexto.

JaCOB, Daniel y Johannes KabateK

2001 "Introducción”, en Jacob y Kabatek (eds.) 2001: VII-XVIII. https://doi.org/10.31819/9783865278432-001

Jасов, Daniel y Johannes KaвAтек (eds.)

2001 Lengua medieval y tradiciones discursivas en la Peninsula Ibérica. Fráncfort del Meno/Madrid: Vervuert/Iberoamericana. https://doi.org/10.31819/9783865278432

JungBluth, Konstanze

2005 Pragmatik der Demonstrativpronomina in den iberoromanischen Sprachen. Tubinga: Niemeyer.

KABATEK, Johannes

2001 "Cómo investigar las tradiciones discursivas medievales? El ejemplo de los textos jurídicos castellanos”. En Jacob y Kabatek (eds.) 2001: 97-132. https://doi.org/10.31819/9783865278432007

KaBATEK, Johannes

2005a “Tradiciones discursivas y cambio lingüístico”. Lexis. XXIX. 2, 151-177. Recogido en Kabatek 2018: 163-183. https://doi. org/10.31819/9783954877508-010

Kabatek, Johannes

2005b "Sobre a historicidade de textos". Trad., José da Silva Simões. Linha d'água. 17, 159-170.

Kabatek, Johannes

2005c Die Bolognesische Renaissance und der Ausbau romanischer Sprachen. Juristische Diskurstraditionen und Sprachentwicklung in Südfrankreich und Spanien im 12. und 13. Jabrbundert. Tubinga: Niemeyer. 
KaBATEK, Johannes

2006 “Tradições discursivas e mudança lingüística”. En Para a bistória do português brasileiro: novos dados, novas análises. Eds., Tânia Lobo y otros. Salvador: Editora da Universidade Federal da Bahia, 505-530.

KABATEK, Johannes

2007 "Las tradiciones discursivas entre conservación e innovación". Rivista di Letterature Ispaniche. 10, 331-348.

KABATEK, Johannes

2012 "Nuevos rumbos en la sintaxis histórica del español". En Montero Cartelle (ed.) 2012: 77-100. Recogido en Kabatek 2018: 123-143. https://doi.org/10.31819/9783954877508-008

KABATEK, Johannes

2013 “Es posible una lingüística histórica basada en un corpus representativo?”, Iberoromania. 77, 8-28. https://doi. org/10.1515/ibero-2013-0045

KABATEK, Johannes

2014 “Lingüística empática”. Rilce. 30, 3, 705-723.

KABATEK, Johannes

2015 "Warum die 'zweite Historizität' eben doch die zweite ist - von der Bedeutung von Diskurstraditionen für die Sprachbetrachtung”. En Diskurse, Texte, Traditionen: Modelle und Fachkulturen in der Diskussion. Eds., Franz Lebsanft y Angela Schrott. Gotinga, V\&R Unipress, 49-62.

KABATEK, Johannes

2018 Lingüistica coseriana, lingüistica histórica, tradiciones discursivas. Eds., Cristina Bleorțu y David Paul Gerards. Madrid/ Fráncfort del Meno: Iberoamericana/Vervuert.

KaBATEK, Johannes (ed.)

2008 Sintaxis histórica del español y cambio lingüistico: nuevas perspectivas desde las Tradiciones Discursivas. Madrid/Fráncfort del Meno: Iberoamericana/Vervuert.

KLoss, Heinz

[1952] 1978 Die Entwicklung neuer germanischen Kultursprachen von 1800 bis 1950. Düsseldorf: Schwann. 
KLoss, Heinz

1967 “Abstandsprache und Ausbausprache”. Anthropological Linguistics. 9, 29-41.

Koch, Peter

1987 Distanz im Dictamen. Zur Schriftlichkeit und Pragmatik mittelalterlicher Brief- und Redemodelle in Italien. Universidad de Friburgo. Tesis de habilitación inédita.

Koch, Peter

1993 "Pour une typologie conceptionelle et médiale des plus anciens documents/monuments des langues romanes". En Le passage à l'écrit des langues romanes. Eds., Maria Selig y otros. Tubinga: Narr, 39-81.

Koch, Peter 1997

"Diskurstraditionen: zu ihrem sprachtheoretischen Status und ihrer Dynamik". En Gattungen mittelalterlichen Schriftlichkeit. Eds., Barbara Frank, Thomas Haye y Doris Tophinke. Tubinga: Narr, 43-79.

$\mathrm{Koch}$, Peter 1998

"Urkunde, Brief und öffentliche Rede. Eine diskurstraditionelle Filiation im 'Medienwechsel'”. Das Mittelalter. Perspektiven mediävistischer Forshung. 3 : 1, 13-44.

$\mathrm{Koch}$, Peter

2008 "Tradiciones discursivas y cambio lingüístico: el ejemplo del tratamiento vuestra merced en español”. En Kabatek (ed.) 2008: 53-88.

Koch, Peter

2021 "Tradições discursivas: de seu status linguístico-teórico e sua dinámica”. Pandemonium. Trad., Alessandra Castilho da Costa. 24, 42, 360-401. https://doi.org/10.11606/198288372442360

Koch, Peter y Wulf Oesterreicher

1985 "Sprache der Nähe - Sprache der Distanz. Mündlichkeit und Schriftlichkeit im Spannungsfeld von Sprachtheorie". Romanistisches Jabrbuch. 36, 15-43. https:// doi.org/10.1515/9783110244922.15 
Koch, Peter y Wulf Oesterreicher

[1990] 2007/2011 Lengua hablada en la Romania: español, francés, italiano. Madrid: Gredos. Versión española de Araceli López Serena del original alemán Gesprochene Sprache in der Romania: Französisch, Italienisch, Spanisch.

Leal Abad, Elena

2011 "La expresión de lo ponderativo en el discurso pre-periodístico. Presencia y función de las oraciones consecutivas de intensidad en la información sobre catástrofes naturales". Revista de Historia de la Lengua Española. 6, 61-86.

Leal Abad, Elena

2016 "Cuando el pasado se hace presente: Usos retrospectivos del presente de indicativo en las relaciones de sucesos del siglo XVII". En El español a través del tiempo. Estudios ofrecidos a Rafael Cano Aguilar. Eds., Araceli López Serena, Antonio Narbona Jiménez y Santiago Del Rey Quesada. Sevilla: Editorial Universidad de Sevilla, 995-1014.

Leal Abad, Elena

2020 "Configuraciones histórica del discurso publicitario como lengua de especialidad: recursos lingüísticos y enunciativos. El anuncio impreso a finales del siglo XVIII". Estudios de Lingüistica del Español. 42, 307-325.

LEBSANFT, Franz

2005 "Kommunikationsprinzipien, Texttraditionen, Geschichte". En Historische Pragmatik und historische Varietätenlinguistik in den romanischen Sprachen. Eds., Angela Schrott y Harald Völker. Gotinga: Universitätsverlag Göttingen, 25-43.

LEBSANFT, Franz

2006 "Sprecher zwischen Tradition und Innovation: Zum Problem von 'Diskurstraditionen' und 'Diskursgemeinschaften' am Beispiel der Sprache der Politik”. Zeitschrift für Romanische Philologie. 122, 531-548. https://doi.org/10.1515/ ZRPH.2006.531

Longhin, Sanderléia Roberta

2014 Tradições discursivas. Conceito, história e aquisição. São Paulo: Cortez. 
Longhin-Thomazi, Sanderléia y Angélica T. Rodrigues

2013 "O estatuto teorico-metodológico do falado e do escrito para a pesquisa em mudança lingüística”. Signo e Sena. 23, 191-212.

Lopes, Célia Regina dos Santos

2011 "Tradição discursiva e mudança no sistema de tratamento do português brasileiro: definindo perfis comportamentais no início do século XX”. Alfa: Revista de lingüística. 55, 2, 361392. https://doi.org/10.1590/S1981-57942011000200002

Lopes-Damasio, Lúcia Regiane

2019 "Construções apositivas: aspectos sintáticos, semánticos e pragmático-discursivos”. En Historia do Português Paulista. Ed., José da Silva Simões. São Paulo: Humanitas, 187-213.

LÓPEZ IZQUIERDo, Marta

2020 Traduction et retextualisation dans la tradition des Fabulae d'Odo de Cheriton. Le rôle des propositions cadratives. Estrasburgo: ELiPhi.

López Serena, Araceli

2006a "La impronta estructuralista de las escuelas de Tubinga y Friburgo. Presente, pasado y futuro de la lingüística de las variedades alemana”. En Caminos Actuales de la Historiografía Lingüistica. Actas del V Congreso Internacional de la Sociedad Española de Historiografía Lingüística. Eds., Antonio Roldán Pérez y otros. Murcia: Universidad de Murcia, 995-1007.

López Serena, Araceli

2006b "Las tradiciones discursivas en la historiografía lingüística y en la historia de la lengua española”. En Fernández Alcaide y López Serena (eds.) 2006: 49-54.

López Serena, Araceli

2011 "La doble determinación del nivel histórico en el saber expresivo. Hacia una nueva delimitación del concepto de tradición discursiva”. Romanistisches Jabrbuch. 62, 59-97.

López Serena, Araceli

2018 “Teorización lingüística, descripción histórica y dimensiones de la variación. El proyecto «Tradiciones discursivas, tradiciones idiomáticas y unidades de análisis del discurso en la historia del español moderno»". En La investigación lingüís- 
tica en Andalucía. XV Jornadas de Lingüistica (Cádiz, 8 y 9 de marzo de 2016). Dirs., Miguel Casas Gómez y María Tarea Díaz Hormigo. Ed., Mario Crespo Miguel. Cádiz: Editorial UCA, 73-94.

López Serena, Araceli

2021 "La tradicionalidad discursiva como materia y las tradiciones discursivas como objeto de estudio". Verba. 48. https://doi. org/10.15304/verba.48.6864

López Serena, Araceli y Daniel M. Sáez Rivera

2018 "Procedimientos de mímesis de la oralidad en el teatro español del siglo XVIII”. Estudios Humanísticos. Filología. 40, 235273. <http://dx.doi.org/10.18002/ehf.v0i40.5566>.

López Serena, Araceli, Santiago Del Rey Quesada y Elena Carmona YANES (eds.)

2020 Tradiciones discursivas y tradiciones idiomáticas en la historia del español moderno. Berlín: Peter Lang.

Marimón Llorca, Carmen

2005 "La investigación histórica sobre tipos de textos en español: problemáticas y perspectivas”. En Actas del IV Congreso Internacional de la SEHL. Nuevas aportaciones a la historiografía lingüística. Ed., Cristóbal Corrales Zumbado. Madrid: Arco/Libros, 1021-1032.

Martí SÁnchez, Manuel

2020 "Construcciones formales y tradiciones discursivas en cuatro textos médicos novatores fundamentales". Revista de Filología Española. 100, 1, 161-193. https://doi.org/10.3989/ rfe.2020.007

Matias, Thiago Trindade

2018 "História da carta de leitor: sobre aspectos composicionais, conservação e dinamismo”. En Andrade y Gomes 2018: 196233.

Méndez García de Paredes, Elena y Elena Leal Abad

2012 "Aspectos lingüísticos propios del discurso pre-periodístico en las relaciones sobre el terremoto de Lisboa de 1755”. Cuadernos Dieciochistas. 13, 75-109. 
Méndez Orense, María

$2021 \quad L a$ tradicionalidad discursiva del texto preensayístico en los siglos XVII y XVIII. Caracterización lingüistica del discurso sobre economía politica de arbitristas y proyectistas. Berlín: Peter Lang.

Menéndez Pidal, Ramón

1951-1956 “Cantos románicos andalusíes”. España, eslabón entre la cristiandad y el Islam. Madrid: Espasa-Calpe, 61-153.

Montero Cartelle, Emilio (ed.)

2012 Actas del VIII Congreso Internacional de Historia de la Lengua Española. Santiago de Compotestela, 14-18 de septiembre de 2009. Coruña: Meubook.

Octavio de Toledo y Huerta, Álvaro S.

2006 "Un rasgo sintáctico del primer español moderno (ca. 16751825): las relaciones interoracionales con ínterin que”. En Fernández Alcaide y López Serena (eds.) 2006: 419-441.

Octavio de Toledo y Huerta, Álvaro S.

2008 "Un nuevo esquema adversativo en el primer español moderno (ca. 1675-1825): la historia del nexo sino es”. En Actas del VII Congreso Internacional de Historia de la Lengua Española. Eds., José G. Moreno de Alba y Concepción Company. Madrid: Arco Libros. Vol. I, 877-907.

Octavio de Toledo y Huerta, Álvaro S.

2011 "Santa Teresa y la mano visible: sobre las variantes sintácticas del Camino de perfección”. En Castillo Lluch y Pons Rodríguez (eds.) 2011: 241-304.

Octavio de Toledo y Huerta, Álvaro S.

2014 "Entre gramaticalización, estructura informativa y tradiciones discursivas: algo más sobre nada”. En Procesos de gramaticalización en la historia del español. Eds., José Luis Girón Alconchel y Daniel M. Sáez Rivera. Madrid/Fráncfort del Meno: Iberoamericana / Vervuert, 263-319.

Octavio de Toledo y Huerta, Álvaro S.

2016 "El aprovechamiento del CORDE para el estudio sintáctico del primer español moderno (ca. 1675-1825)”. En Lingüística 
de corpus y lingüistica histórica iberorrománica. Ed., Johannes Kabatek. Berlín/Boston: De Gruyter, 57-89.

Octavio de Toledo y Huerta, Álvaro S.

2017 "Juan de Mena como traductor: aspectos lingüísticos del Omero romançado". En Romanische Sprachgeschichte und Übersetzung. Eds., Heidi Aschenberg y Sarah Dessì-Schmidt. Heidelberg: Winter, 53-114.

Octavio de Toledo y Huerta, Álvaro S.

2018 “'Tradiciones discursivas o tradicionalidad? ¿Gramaticalización o sintactización? Difusión y declive de las construcciones modales con infinitivo antepuesto". En Procesos de textualización y gramaticalización en la historia del español. Eds., José Luis Girón Alconchel, Francisco Javier Herrero Ruiz de Loizaga y Daniel M. Sáez Rivera. Madrid/ Fráncfort del Meno: Iberoamericana/Vervuert, 79-134.

Octavio de Toledo y Huerta, Álvaro S.

2019 "Sintaxis de la prosa del instante: la lengua de una tradición efímera en los albores del siglo XIX”. Anuari de Filologia. Estudis de lingüística. 9, 91-144. https://doi.org/10.1344/ AFEL2019.9.4

Octavio de Toledo y Huerta, Álvaro S.

2020 "La lengua en la corte de Carlos IV: rasgos morfosintácticos de la novela culta en los albores del siglo XIX”. En Araceli López Serena y otros (eds.) 2020: 51-134.

Oesterreicher, Wulf

1997 “Zur Fundierung von Diskurstraditionen”. En Gattungen mittelalterlichen Schriftlichkeit. Eds., Barbara Frank, Thomas Haye y Doris Tophinke. Tubinga: Narr, 19-41.

Oesterreicher, Wulf

2001 "La «recontextualización» de los géneros medievales como tarea hermenéutica”. En Jacob y Kabatek (eds.) 2001: 199-232. https://doi.org/10.31819/9783865278432-011

OESTERREICHER, Wulf

2002 "Sprachwandel - Corpusbefunde, Sprachregeln, kognitive Konstanten”. Romanistisches Jabrbuch. 53, 31-55. https://doi. org/10.1515/9783110179590.31 
OESTERREICHER, Wulf

2003 "Autonomización del texto y recontextualización. Dos problemas fundamentales de las ciencias del texto”. En Homenaje a Luis Jaime Cisneros. Ed., Eduardo Hopkins Rodríguez. Lima: Pontifica Universidad Católica del Perú, 343-387.

Oesterreicher, Wulf

2004 "Textos entre inmediatez y distancia comunicativas. El problema de lo hablado escrito en el Siglo de Oro”. En Historia de la lengua española. Coord., Rafael Cano Aguilar. Barcelona: Ariel, 729-769.

Oesterreicher, Wulf

2006 "La historicidad del lenguaje. Variación, diversidad y cambio lingüístico". En Actas del VI Congreso Internacional de Historia de la Lengua Española (Madrid, 29 de septiembre-3 de octubre 2003). Eds., José Jesús de Bustos Tovar y José Luis Girón Alconchel. Madrid: Universidad Complutense de Madrid/Arco Libros/Asociación de Historia de la Lengua Española. Vol. 1, 137-158.

Oesterreicher, Wulf

2007 "Gramática histórica, tradiciones discusivas y variedades lingüísticas. Esbozo programático”. Revista de Historia de la Lengua Española. 1, 109-128.

Oesterreicher, Wulf

2008 "Dinámicas de estructuras actanciales en el Siglo de Oro: el ejemplo del verbo encabalgar”. En Kabatek (ed.) 2008: 225248.

Oesterreicher, Wulf

2011a "Conquistas metodológicas en la lingüística diacrónica actual. La historicidad del lenguaje: lenguas, variedades y tradiciones discursivas en el marco de una semiótica social”. En Castillo Lluch y Pons Rodríguez (eds.) 2011: 305-334.

Oesterreicher, Wulf

2011b "Referencialidad y tradiciones discursivas". En Sintaxis y análisis del discurso hablado en español. Homenaje a Antonio Narbona. Coords., José Jesús de Bustos Tovar, Rafael Cano Aguilar, Elena Méndez García de Paredes y Araceli López 
Serena. Sevilla: Servicio de Publicaciones de la Universidad de Sevilla. Vol. II, 887-906.

Oesterreicher, Wulf

2012 "Innovación y cambio gramatical: formulaciones ad hoc, difusión de innovaciones y formas del cambio lingüístico”. En Montero Cartelle (ed.) 2012: 228-246.

Oesterreicher, Wulf, Eva Stoll y Andreas Wesch (eds.)

1998 Competencia escrita, tradiciones discursivas y variedades lingüísticas. Aspectos de español europeo y americano de los siglos XVI y XVII. Tubinga: Narr.

PONS BORDERÍA, Salvador

2008 "Gramaticalización por tradiciones discursivas: el caso de esto es”. En Kabatek (ed.) 2008: 249-274.

Pons Rodríguez, Lola

2006a "Retórica y tradiciones discursivas". En Fernández Alcaide y López Serena (eds.) 2006: 67-78.

Pons Rodríguez, Lola

2006b "Una reflexión sobre el cambio lingüístico en el siglo $\mathrm{XV}$ ". Actas del V Congreso Andaluz de Lingüística General. Homenaje a J.A. de Molina Redondo. Granada: Granada Lingvistica-Serie Collectae. Vol. III, 1563-1577.

Pons Rodríguez, Lola

2007 "La qual çibdad: las relativas con antecedente adjunto del siglo XIII a hoy: evolución de un procedimiento cohesivo". Romanistisches Jabrbuch. 58, 275-305. https://doi.org/10.1515/9783 110206661.2.275

Pons Rodríguez, Lola

2008 "El peso de la tradición discursiva en un proceso de textualización: un ejemplo en la Edad Media castellana”. En Johannes Kabatek (ed.) 2008: 197-224.

Pons Rodríguez, Lola

2010a "La elaboración léxica desde modelos latinos: tres estudios de caso en el castellano medieval (inclusive, exclusive, respective)". En Modelos latinos en la Castilla medieval. Eds., Mónica Cas- 
tillo y Marta López Izquierdo. Madrid/Fráncfort del Meno: Iberoamericana / Vervuert, 81-111.

Pons Rodríguez, Lola

2010b "Los marcadores del discurso en la historia del español". En Los estudios sobre marcadores del discurso en español, boy. Coords., Óscar Loureda y Esperanza Acín. Madrid: Arco/ Libros, 523-615.

PONS Rodríguez, Lola

2014 "Prejuicios y apriorismos en la investigación histórica sobre marcadores discursivos (con algunas notas sobre así las cosas)". En Marqueurs $d u$ discours dans les langues romanes: une approche contrastive. Eds., Margarita Borreguero Zuloaga y Sonia Gómez-Jordana Ferrary. Limoges: Lambert Lucas, 31636.

RAIBLE, Wolfgang

1992 Junktion. Eine Dimension der Sprache und ibre Realisierungsformen zwischen Aggregation und Integration. Heidelberg: Carl Winter.

RENWICK, Ricardo

1997 "El proyecto de investigación escritura de impronta oral en la historiografía colonial de Hispanoamérica: 1500 a 1615. Fundamentos teóricos y metodología”. Lexis. XXI, 1, 17-52.

RIDRUEJO, Emilio

1990 "Calcos reanálisis y procesos analógicos en la sintaxis del español preclásico”. En Homenaje al profesor Lapesa. Coord., José Muñoz Garrigós. Universidad de Murcia: Servicio de Publicaciones, 205-226.

Rivarola, José Luis

2000 Español andino. Textos de bilingües de los siglos XVI y XVII. Madrid/Fráncfort del Meno: Iberoamericana/Vervuert.

Rivarola, José Luis

2007 "La formación de un objeto histórico: a propósito del español de América”. En Sprachgeschichte und Geschichte der Sprachwissenschaft. Eds., Daniel Jacob y Thomas Krefeld. Tubinga: Narr, 169-178. 
Rivarola, José Luis

2009 Documentos lingüísticos del Perú. Siglos XVI y XVII. Madrid: CSIC.

SÁez Rivera, Daniel M.

2006 "Tradiciones discursivas, historiografía lingüística e historia de la lengua”. En Fernández Alcaide y López Serena (eds.) 2006: 89-111.

Schlieben-Lange, Brigitte

1983 Traditionen des Sprechens. Elemente einer pragmatischen Sprachgeschichtsschreibung. Stuttgart: Kohlhammer.

SCHMidT-Riese, Roland

1997 "Schreibkompetenz, Diskurstraditionen und Varietätenwahl in früher Kolonialhistoriographie Hispanoamerikas". Zeitschrift für Literaturwissenschaft und Linguistik. 108, 45-86.

SiMÕES, José da Silva

2007 Sintactização, discursivização e semantização das orações de gerundio no português brasileiro. São Paulo: Universidade de São Paulo. Tesis doctoral.

SimÕES, José da Silva

2017 "O corpus do Projeto Para a Hitória do Português Brasileiro: a constitução de corpora históricos baseada em criterios de tradições discursivas”. Gallecia. Estudos de lingüística portuguesa e galega. 38, 683-695. https://doi.org/10.15304/ cc.2017.1080.38

SimÕES, José da Silva

2020 Corpus Histórico do Português Paulista: história de textos e história da língua. São Paulo: Universidade de São Paulo. Tesis de habilitación.

Simões, José da Silva y Alessandra Castilho da Costa

2009 "As atas paroquiais de batismo, casamento e óbito como géneros discursivos". En Linhas e entrelinhas: as diferentes leituras das atas paroquiais dos setecentos. Eds., Maria Silvia C. Beozzo Bassanezi y Tarcísio R. Botelho. Belo Horizonte: Veredas \& Cenários, 35-58. 
Simões, José da Silva y Verena Kewitz

2006 "Traços lingüístico-discursivos em corpora do português brasileiro”. Estudos Linguísticos. XXXV, 1018-1027.

Simões, José da Silva y Verena Kewitz

2009a "A constituição de corpora diacrónicos do português brasileiro e seus traços linguístico-discursivos". En Estudos sobre o Português Brasileiro. Eds., Eberhard Gärtner y Axel Schönberger. Fráncfort del Meno: Valentia, 31-48.

SimÕes, José da Silva y Verena KewiTZ

2009b "Normas linguísticas, história social, contatos linguísticos e tradições discursivas: transformando encruzilhadas em novos caminos para a constitução de corpora diacrónicos”. En História do Português Paulista. Ed., Ataliba Teixeira de Castilho. Campinas: PUBLIEL-FAPESP. Vol. 1, 699-720.

SPITZER, Leo

[1955] 1982 Lingüistica e historia literaria. Madrid: Gredos.

STOLL, Eva

1994 "Observaciones sobre las tradiciones discursivas en la historiografía indiana: los Naufragios de Alvar Núñez Cabeza de Vaca”. En Lengua y cultura en el Caribe hispánico. Eds., Jens Lüdkte y Matthias Perl. Tubinga: Max Niemeyer, 77-89.

STOLL, Eva

1996

"Competencia escrita de impronta oral en la crónica soldadesca de Pedro Pizarro". En El español hablado y la cultura oral en España e Hispanoamérica. Eds., Thomas Kotschi, Wulf Oesterreicher y Klaus Zimmermann. Fráncfort del Meno: Vervuert, 427-446.

STOLL, Eva

1997

Konquistatoren als Historiographen - Diskurstraditionelle und textpragmatische Aspekte in Texten von Francisco de Jerez, Diego de Trujillo, Pedro Pizarro und Alonso Borregán. Tubinga: Narr.

STOLL, Eva

1998 "Géneros en la historiografía indiana: modelos y transformaciones”. En Oesterreicher, Stoll y Wesch (eds.) 1998: 143-168. 
STOLL, Eva

2005

"Jurisconsultos, secretarios y suplicantes: el sello jurídico del discurso historiográfico colonial”. En Talleres de la memoria. Reivindicaciones y autoridad en la bistoriografía indiana de los siglos XVI y XVII. Eds., Robert Folger y Wulf Oesterreicher. Münster: LIT, 225-245.

STOLL, Eva 2010

"Santiago en los andes. Vicisitudes de los santos en la sociedad colonial”. En Catequesis y derecho en la América colonial. Fronteras borrosas. Ed., Roland Schmidt-Riese. Madrid/ Fráncfort del Meno: Iberoamericana/Vervuert, 97-115.

VÁZQuez Laslop, María Eugenia

2014a "Tradiciones e innovaciones jurídicas y textuales: codificación y descodificación en las leyes mexicanas de los siglos XIX al XXI”. En Prácticas y políticas lingüísticas. Nuevas variedades, normas, actitudes y perspectivas. Ed., Klaus Zimmermann. Madrid/Fráncfort del Meno: Iberoamericana/Vervuert, 167204.

VÁzQuez Laslop, María Eugenia

2014b "Tradiciones jurídicas y tradiciones textuales de las leyes mexicanas (siglos XVI al XXI)". Cuadernos de la ALFAL. 6, 87-104.

VÁzQuez Laslop, María Eugenia

2015 "Del derecho castellano a la codificación: paradigmas jurídicos y tradiciones textuales en las leyes mexicanas del siglo XIX”. En Actas del IX Congreso Internacional de Historia de la Lengua Española. Eds., José María García Martín, Francisco Javier de Cos Ruiz y Mariano Franco Figueroa. Madrid/ Fráncfort del Meno: Iberoamericana/Vervuert. Vol. 2, 21882201.

VÁzQuez Laslop, María Eugenia

2018 "Los ritmos de las tradiciones jurídicas y textuales: historicidad, entornos y hermenéutica". En Repenser la variation linguistique. Actes du Colloque DIA IV à Zurich (12-14 sept. 2016). Eds., Johannes Kabatek, Harald Völker y Martin-Dietrich Glessgen. Estrasburgo: Éditions de Linguistique et de Philologie, 155-168. 
VÁZQuez Laslop, María Eugenia

2019a "Cohesión sintáctica y argumentación en las leyes mexicanas del siglo XIX”. En Actas del X Congreso Internacional de Historia de la Lengua Española. Zaragoza, 7-11 de septiembre de 2015. Eds., María Luisa Arnal Purroy, Rosa María Castañer Martín, José María Enguita Utrilla, Vicente Lagüéns Gracia y María Antonia Martín Zorraquino. Zaragoza: Institución Fernando el Católico. Vol. 2, 2017-2032.

VÁzQuez Laslop, María Eugenia

2019b "Historicidad textual y tradiciones culturales, con especial referencia a las disposiciones legislativas en México". Historia Mexicana. 272, 1743-1792. https://doi.org/10.24201/ hm.v68i4.3862

VIERA, Hernán

2020 "El fruto de sus predecesoras. El rol de las tradiciones discursivas en la conformación de los géneros de prensa en el Uruguay del siglo XIX”. En Bertolotti y Coll (coords.) 2020: 19-41.

WesCh, Andreas

1994 "El documento indiano y las tradiciones textuales en los siglos XV y XVI”. En El español de América en el siglo XVI. Actas del Simposio del Instituto Ibero-americano de Berlín. Ed., Jens Lüdkte. Madrid/Fráncfort del Meno: Iberoamericana/Vervuert, 57-71.

Wesch, Andreas

1998 "Hacia una tipología lingüística de los textos administrativos y jurídicos españoles (siglos XV-XVII)”. En Oesterreicher, Stoll y Wesch (eds.) 1998: 187-218.

Wesch, Andreas

2005 "Spanish documents of the $15^{\text {th }}, 16^{\text {th }}$ and $17^{\text {th }}$ centuries from a pragmatic point of view”. En Romanistische Korpuslinguistik II. Korpora und diachrone Sprachwissenschaft. Eds., Claus D. Pusch, Johannes Kabatek y Wolfgang Raible. Tubinga: Narr, 187-218. 
WesCh, Andreas

2006 "Cambio medial y huellas de lo oral en pareceres protocolizados de los siglos XV y XVI”. En Actas del VI Congreso Internacional de Historia de la Lengua Española (Madrid, 29 de septiembre-3 de octubre de 2003). Eds., José Jesús de Bustos Tovar y José Luis Girón Alconchel. Madrid: Arco/Libros, 2949-2958.

WiLHelm, Raymund

2001 "Diskurstraditionen". En Language Typology and Language Universals - Sprachtypologie und sprachliche Universalien La typologie des langues et les universaux linguistiques. An International Handbook - Ein internationals Handbuch Manuel international. Eds., Martin Haspelmath, Ekkerhard König, Wulf Oesterreicher y Wolfgang Raible. Berlín/Nueva York: De Gruyter. Vol. 1, 467-477.

Winter-Froemel, Esme, Araceli López Serena, Álvaro Octavio de Toledo y Huerta y Barbara Frank-Job (eds.)

2015 Diskurstraditionelles und Einzelsprachliches im Sprachwandel. Tubinga: Narr.

Zamorano Aguilar, Alfonso

2020 "Tradiciones discursivas (TD) y series textuales (ST): convergencias y divergencias teóricas”. En López Serena, Del Rey Quesada y Carmona Yanes (eds.) 2020: 485-509.

Zavam, Aurea

2009 "Historiando uma tradição discursiva: a construção da autoria institucional em editoriais de jornais cearenses”. Encontros de Vista. 3, 1-16.

Recepción: 15/04/2021 Aceptación: 19/07/2021 